\title{
OBRAS ESPAÑOLAS SOBRE HISTORIA NATURAL Y MATERIA MEDICA AMERICANAS EN LA ITALIA DEL SIGLO XVI
}

\section{José Pardo Tomás}

La difusión en Europa de la historia natural y la materia médica del Nuevo Mundo se realizó, en gran medida y como es lógico suponer, a través de las obras que sobre estos temas publicaron autores hispanos. Una mirada general a esta producción impresa y a su difusión europea, a través de ediciones y traducciones fuera de la Península Ibérica, señala de forma indudable a Italia como el ámbito geográfico en el que tuvieron más rápida y mayor repercusión (1).

Vamos a centrar nuestra atención en las obras que nos parecen más significativas desde el punto de vista de su contenido sobre historia natural y materia médica americanas. No consideraremos, pues, en este trabajo, obras como las de Hernán Cortés (reeditado hasta cinco veces en Italia durante el período 1522-1565), así como tampoco las obras sobre el Nuevo Mundo aparecidas en los primeros años, ya que consideramos que merecen por sí solas un estudio aparte y que además se alejan del interés específicamente históriconatural o médico (2). Así pues, analizaremos aquí sola- 
mente una decena de obras, pero que conocieron un total de cuarenta y dos ediciones italianas a lo largo del siglo XVI.

Veamos, en primer lugar, de qué obras se trata y cómo fueron apareciendo las ediciones en Italia. El proceso de difusión estudiado puede dividirse, atendiendo al ritmo de aparición de las ediciones, en cuatro fases diferentes.

\section{La primera fase: Francisco Delicado y Gonzalo Fernández}

de Oviedo (1529-1535)

La primera obra española directamente relacionada con la materia médica americana publicada en Italia fue el opúsculo de Francisco Delicado El modo de adoperare el legno de India occidentale (3), aparecido en Venecia, en 1529 (4). El propio Delicado costeó la edición y él mismo la escribió, en parte, en un italiano un tanto pintoresco (5). El texto, pese a su brevedad, no deja de resultar interesante para conocer la visión que de la sífilis y de los problemas terapéuticos a ella ligados se tenía en esos años, sobre todo por lo que respecta al uso, ya relativamente extendido, del guayaco. Pero también para nuestro objeto de estudio, la obra contiene información valiosa.

En efecto, Delicado incluyó, directamente en castellano, un fragmento (6) del Sumario de la historia natural, que Gonzalo Fernández de Oviedo había publicado tres años antes, en 1526, en Toledo. Se trata, en concreto, del capítulo 76, dedicado precisamente a la descripción del guayaco. Delicado, además, nos cuenta cómo llegó a él el texto de Oviedo:

«Siendo venido a esta inclita cividad de Venecia después de la dispersión de los ecclesiasticos que en Roma nos hallamos.[se refiere al llamado "saco de Roma" por las tropas de Carlos V, en 1527] halle que un embaxador desta prudentissima e serenissima Señoria que en España era estado truxo el libro del Señor Oviedo y porque me parecio que dize mui bien en todo, maxime deste legno santo, tome el precedente capitulo suyo y puselo en mi obra...» (7).

El embajador veneciano era, como veremos, Andrea Navagero, quien había regresado a Venecia en 1528, trayendo consigo, entre otras obras, el Sumario de Oviedo (8).

Será precisamente esta obra la siguiente en aparecer traducida y editada en Italia. En 1534, en Venecia también, el impresor Niccolò Zoppino 
editó de forma conjunta tres obras sobre las Indias occidentales (9); la de Fernández de Oviedo apareció como Libro secondo (10), siendo el libro primero una reestructurada traducción de las tres primeras décadas de Pedro Mártir de Anglería (11). El nombre del traductor no figuraba en la portada y, como veremos, no parece haber acuerdo sobre su identidad; sin embargo sí parece claro que el responsable último de la edición en su conjunto fue Giovanni Battista Ramusio (12).

- El Sumarioffue también traducido y editado en Roma apenas un año después de la edición venéciana (13), sin que conste tampoco en esta ocasión el nombre del traductor. Después de 1535, se abrió un prolongado paréntesis de veinte años, a lo largo de los cuales no se publicó ninguna obra española sobre argumento americano. Tras este prolongado vacío, sin embargo; se inició una șegunda etapa, de más amplio alcance.

2. La segunda fase: la historia natural americana a través de los cronistas (1555-1566)

A lo largo de los doce años que abarca este período, fueron apareciendo cinco obras nuevas, a la vez que se reeditaba dos veces más el Sumario de Oviedo. Estas nuevas obras se caracterizan, en primer lugar, por formar parte de la primera gran generación de cronistas españoles de Indias y, en segundo lugar, por presentar el más rico contenido en información sobre la historia natural americana que podía ofrecerse, en letra impresa, en esos años.

El período se abrió en 1555, con la publicación en Roma, por parte de los hermanos Valerio y Luigi Dorico, de la Crónica del Peru, de Pedro Cieza de León (14) y de la Conquista de Mexico, de Francisco López de Gómara (15), traducidas ambas por Agustín de Cravaliz, un donostiarra afincado en Roma. Del mismo traductor y por los mismos impresores, se publicó, al año siguiente, la primera parte de la Historia General de las Indias, de López de Gómara (16).

Estas tres obras obtuvieron un notable éxito en Italia, a juzgar por las seis reediciones que cada una de ellas iba a conocer antes de que finalizara el siglo. Pero si Roma había sido el escenario de la aparición de las primeras ediciones, toda la producción posterior de estos autores se realizaría desde Venecia.

En 1556, Andrea Arrivabene imprimnió la Cronica de Cieza, titulándola Prima parte dell'istore del Peru, en una traducción anónima, algo diferente a la aparecida el año anterior en Roma de la mano de Cravaliz (17). Al 
año siguiente, el mismo impresor veneciano editó la Historia general de Gómara, bajo el título La seconda parte delle historie generali dell'Indie (18). Parece evidente, que Arrivabene prentendió dar una unidad a ambas crónicas americanas, de ahí el cambio de título (19). Por otro lado, también esta traducción anónima de la obra de Gómara es claramente distinta de la romana (20).

Solamente tres años después, en 1560, volvieron a reeditarse las obras en Venecia, pero esta vez la traducción llevada a las prensas por Francesco Lorenzini da Torino fue la de Agustín de Cravaliz (21). Sin embargo, en el mismo año 1560, otro impresor veneciano, Giordano Ziletti, volvía a imprimir la traducción anónima de 1556 (22).

Entre 1564 y 1566 volvió a repetirse este doble proceso de reediciones. Las tres traducciones de Cravaliz fueron reeditadas por Giovanni Bonadio como tres partes de unas mismas Historias de las Indias. Casi al mismo tiempo, Giordano Ziletti, por su parte, siguió dando salida a la traducción anónima de las dos primeras partes, añadiendo en esta ocasión una traducción, obra de Lucio Mauro, de la Conquista de Mexico de Gómara, que hasta entonces (1566) (23) sólo había sido editada en la traducción de Cravaliz. La compleja historia editorial de estas obras (24) no acabó aquí, como veremos más adelante.

Otra de las obras de cronistas españoles traducida en este período fue la Historia del descubrimietno y conquista del Peru, de Agustín de Zárate, que apareció en Venecia, en 1563, en la versión italiana realizada por Alfonso de Ulloa (25).

Pero, indudablemente, la obra más importante aparecida en este período, desde el punto de vista de la historia natural, es la primera parte de la Historia natural y general de las Indias, de Fernández de Oviedo. El autor era ya conocido en Italia a través de las dos ediciones del Sumario, aparecidas en la primera fase. En estos años centrales del siglo, aparecerá la traducción de la Historia, junto con la reedición de la del Sumario, en el marco déla gran recopilación enciclopédica sobre los descubrimientos geográficos "llevada a cabo por Giambattista Ramusio. El tercer volumen de sus Navigationi et viaggi (26), impreso por Tommaso Giunta en 1556, está íntegramente dedicado al continente americano y en él incluyó Ramusio las dos obras de Oviedo, además de las Relaciones de Hernán Cortés, las tres primeras décadas de Anglería y otras relaciones de viajes escritas por autores hispanos y franceses (27).

Este tercer volumen de la recopilación ramusiana se reimprimió en 1565 (28), nuevamente en el taller veneciano de los Giunta. En esta segunda edición aparecía finalmente en la portada el nombre de Ramusio, ya que 
como el mismo Tommaso Giunta explicaba en el proemio del segundo volumen (29), aparecido en 1559, poco después de la muerte del secretario veneciano, éste no quiso nunca que su nombre figurara en la obra.

La trayectoria editorial de las obras de Oviedo en Italia finaliza en 1566. Ese año, en casa de Giordano Ziletti, se imprimió el primer volumen de la recopilación de Luigi Luigini de tratados sobre el morbo gallico (30). En él, aparecía la traducción latina de los dos capítulos que Oviedo había dedicado al guayaco en su Historia general (31).

Con la aparición de esta obra se cierra este segundo período, en el que, en doce años, se alcanzó el número de veintiuna ediciones. Tras estos años de gran actividad, se abrió de nuevo un paréntesis en el que la producción editorial decayó, aunque durante un lapso de tiempo menor que el de los años cuarenta de la centuria. Transcurridos nueve años, puede decirse que se inició una nueva fase en el proceso de difusión de estas obras.

\section{La tercera fase: Monardes y la materia médica (1575-1589)}

En 1575, un impresor veneciano que ya nos resulta conocido, Giordano Ziletti, editó la traducción italiana de las dos primeras partes de la obra de Nicolás Monardes De las cosas que se traen de nuestras Indias Occidentales, que sirven al uso de la medicina (32). El traductor, como tantas otras veces en casa de los Ziletti, no figuraba en la portada, sino que era el propio impresor quien se hacía cargo de escribir la dedicatoria, el aviso a los lectores y, es de suponer, costeaba la edición. En el texto Ai lettori, Ziletti anunciaba la existencia de la tercera parte de la obra de Monardes (33) y su intención de publicarla:

«...ne mancherò nell'avenire come mi giunga la terza parte promessa dall'Autore, di farvene subito partecipi» (34).

Pese a la intención del editor, la traducción de la tercera parte nunca llegó a aparecer en Italia. En este año de 1575, cuando se imprimían las dos primeras partes, Monardes no era un autor completamente inédito en territorio italiano. En 1570, en Milán, se había publicado la traducción del capítulo sobre la raíz de Mechoacán (35), y en 1574, esta vez en Florencia, Giovanni Battista Scarampo había dado a la imprenta una versión italiana del Libro de la Nieve, que acompañaba la segunda parte de la obra de Monardes, en la' edición sevillana de 1571 (36). Pero la 
difusión de la gran aportación del médico sevillano se realizó desde el ámbito veneciano, a partir de 1575 , cuando, como hemos dicho, apareció la edición completa de las dos primeras partes.

Sin embargo, en esta ocasión, también se produjeron problemas de dobles ediciones, como había ocurrido con las obras de Gómara y Cieza. En 1576, siempre en Venecia pero de impresor desconocido, apareció una traducción de los Dos libros..., realizada por un médico de Chieti llamado Annibale Briganti. La edición reunía también la versión italiana del tratado de Garcia da Orta sobre los simples de las Indias. Orientales y de los comentarios a éste realizados por $\mathrm{C}$. Clusius y publicados en latín, en Amberes, en 1574 (37).

Esta duplicidad en las ediciones de Monardes se mantuvo en las reediciones siguientes. Así ocurrió en 1582, cuando Giordano Ziletti reimprimió su edición de 1575 y el sobrino de éste, Francesco Ziletti, hizo otro tanto con la traducción de Briganti, siempre unida al texto de Garcia da Orta. Nuevamente en 1589, los Ziletti abordaron la reimpresión de ambas ediciones (38). Una atenta mirada deja claramente establecido que la traducción de Briganti abarcaba solamente la primera parte, suprimiendo además, en la de 1576, el capítulo primero del segundo libro, dedicado a los venenos. Por el contrario las ediciones de la otra traducción anónima, contenían el texto completo de las dos primeras partes.

Aunque las ediciones venecianas son, como hemos señalado, las más exhaustivas, no faltaron otras ediciones parciales. Además de las de Florencia y Milán ya citadas, debemos añadir la que en 1578 se efectuó en Génova, que contenía la traducción de dos capítulos de la segunda parte de la obra de Monardes, los dedicados al tabaco (libro primero, capítulo primero) y a la Pimienta luenga (libro segundo, capítulo noveno), dos destacados productos de la materia médica indiana (39).

El período que ahora comentamos fue, pues, rico en cuanto a la difusión de la obra capital sobre la materia medicinal americana. Pero en este mismo período otra obra hispana, la que el portugués Cristóbal Acosta publicara en castellano en Burgos en 1578, conoció también su traducción italiana, de la mano del editor veneciano Francesco Ziletti (40). Si bien la obra de Acosta, como es sabido, se ocupa principalmente de materia médica de origen asiático, la hemos considerado en nuestro estudio por varios motives. El primero y principal es porque el contenido de la obra ofrece noticias sobre plantas de origen americano (como el ánanas, o piña tropical, de la cual se incluye una de las primeras representaciones gráficas). El segundo motivo es que la edición de Acosta en Italia responde, como veremos, a un proyecto editorial de los Ziletti en el que se incluían 
tanto Monardes y Acosta, como Garcia da Orta y otros autores. No es casual, en este sentido, que fuera el propio Francesco Ziletti quien, precisamente en la presentación a los lectores de la obra de Acosta, recordara a su público que se hallaba aún:

«aspettando la terza parte del Dottor Monardes già tanto desiderata da voi, la qual tuttavia è sotto le Stampe» (41).

Para concluir con las ediciones aparecidas a lo largo de esta tercera fase, señalemos que.las obras de López de.Gómara y la de Cieza volvieron a reeditarse en estos años, concretamente en 1576. La traducción elegida esta vez por el impresor Camillo Franceschini fue la de Agustín de Cravaliz.

Así pues, a lo largo de estos catorce años, encontramos un total de trece ediciones, nueve de las cuales corresponden a la obra de Monardes, lo que le da un particular significado a este período. Después de 1589, se volvió a abrir un pequeño paréntesis en la producción de ediciones de textos hispanos, que se prolongó hasta 1596.

\section{La cuarta fase: el intento de interpretación de José de Acosta} $y$ las reediciones de final de siglo (1596-1599)

En los últimos cuatro años de la centuria, encontramos cinco ediciones, cuatro de las cuales son reimpresiones de obras ya aparecidas en años anteriores. Concretamente, se reeditó nuevamente la Crónica de Cieza de León (Venecia, Arrivabene, 1596); volvieron a imprimirse, en la traducción de Lucio Mauro, las dos obras de López de Gómara (Venecia, Barezzo Barezzi, 1599); y se llevó a cabo la última reedición de Monardes en el siglo XVI, efectuada por los herederos de Girolamo Scotto, en Venecia, en 1597, reproduciendo la traducción de Annibale Briganti, siempre junto al texto de Garcia da Orta y los comentarios de Clusius.

La novedad del período fue la traducción de la Historia natural y moral de las Indias, del jesuita español José de Acosta. La obra había aparecido en castellano seis años antes, en Sevilla. La traducción era de Giovanni Paolo Galluci y fue impresa por Bernardo Basa en Venecia (42). La versión italiana se basó, fundamentalmente, en la segunda edición española, que había tenido lugar en Barcelona, en 1591 (43). Por otra parte, un no bien explicado problema con la censura mutiló parte del 
quinto libro de la obra, el que Acosta había dedicado a la «historia moral». Así lo advertía el propio Galluci:

«Non paia strano all'Autore di questa Historia, nemeno à chi l'hà letta nella lingua Spagnuola, che in questo quinto libro manchino molte cose scritte da lui, che si legono nello Spagnuolo, perché cosi è piacciuto ai superiori, c'hanno ordine di vedere le cose che si stampano, ai quali non solo siamo sforzati obedire: ma debbiamo obedir volontieri» (44).

Con la difusión de la síntesis históriconatural de Acosta, obra que recogía el saber accesible en la época sobre estas materias y trataba de ofrecer por vez primera un marco interpretativo global, se cerraba realmente la etapa más intensa de la difusión de obras hispanas sobre tema americano.

En el siglo siguiente, aunque con un ritmo muy diferente y con un retraso considerable, la difusión prosiguió. Monardes se reeditó aún varias veces (45); también se hicieron reediciones de Acosta (46) y Fernández de Oviedo, a través de la recopilación ramusiana (47). Pero los grandes protagonistas de este proceso en el siglo XVII son, en primer y destacado lugar, Francisco Hernández, seguido de Juan Fragoso y de Antonio Colmenero de Ledesma (48).

En la tabla 1 hemos tratado de sintetizar de un modo más gráfico la distribución de todas las ediciones aquí citadas a lo largo de los setenta años que abarcan los cuatro períodos comentados (49).

\section{La rapidez de la difusión en Italia}

Hemos visto hasta ahora el desarrollo cronológico de las ediciones y su periodización. Pero es evidente la necesidad de responder a la cuestión de con qué retraso, con respecto a la aparición de las ediciones originales, se produjeron las italianas. La tabla 2 trata de mostrar la respuesta a esa cuestión.

Como se desprende de la lectura de los datos de la tabla 2, si exceptuamos el caso anómalo de la Historia general y natural de Fernández de Oviedo, todas las obras se tradujeron y difundieron en Italia con una media de cinco años de diferencia con respecto a la aparición de la primera edición castellana. Tal rapidez en la difusión no se alcanzaba fácilmente en la época, ni siquiera en el caso de libros de materias más asequibles al público en general. 


\section{TABLA 1}

Distribución de ediciones italianas de obras españolas sobre historia natural y materia médica americanas (1529-1599)

\begin{tabular}{ll}
\hline Año & \\
\hline 1529 & Delicado \\
1534 & Oviedo (a) \\
1535 & Oviedo (a) \\
1555 & Cieza, Gómara (a) \\
1556 & Cieza, Gómara (b), Oviedo (a) (b) \\
1557 & Gómara (a) (b) \\
1560 & Cieza (2), Gómara (a) (b) \\
1563 & Zárate \\
1564 & Cieza, Gómara (a) (b) \\
1565 & Gómara (a), Oviedo (a) (b) \\
1566 & Gómara (b), Oviedo (b, parcial) \\
1570 & Monardes (parcial) \\
1574 & Monardes (parcial) \\
1575 & Monardes \\
1576 & Monardes, Cieza, Gómara (a) (b) \\
1578 & Monardes (parcial) \\
1582 & Monardes (2) \\
1585 & C. Acosta \\
1589 & Monardes (2) \\
1596 & J. Acosta, Cieza \\
1597 & Monardes \\
1599 & Gómara (a) (b) \\
\hline
\end{tabular}

Las obras de Cieza y López de Gómara, junto a la de Monardes, son las que más rápida acogida tuvieron. Conviene subrayar, además que las traducciones italianas fueron en casi todos los casos las primeras ediciones no castellanas aparecidas; sólo debemos exceptuar los casos de Monardes y de Cristóbal de Acosta, cuyas obras fueron traducidas al latín por Clusius (Amberes, 1574) uno y tres años antes, respectivamente, de la aparición de la edición italiana.

El caso de retraso más prolongado es el de la Historia de Oviedo, que se difundió en Italia más de veinte años después de su primera edición española (Sevilla, 1535). Debemos tener en cuenta que es precisamente 


\section{TABLA 2}

Comparación entre los años de publicación de las primeras ediciones castellanas e italianas de las obras sobre historia natural y materia médica americanas aparecidas en Italia en el s. XVI

\begin{tabular}{|c|c|c|c|}
\hline Autor & Ed. castellana & Ed: italiana & Años diferencia \\
\hline Delicado. & - & $\therefore 1529$ & - \\
\hline Oviedo (a) & 1526 & 1534 & 8 \\
\hline Oviedo (b) & 1535 & $\because \quad 1556$ & $\cdot 21$ \\
\hline Cieza & 1553 & $\quad 1555$ & 2 \\
\hline Gómara (a) & 1553 & 1555 & 2 \\
\hline Gómara (b) & 1552 & 1556 & 4 \\
\hline Zárate & 1555 & 1563 & 8 \\
\hline Monardes & 1571 & 1575 & $4^{*}$ \\
\hline C. Acosta & 1578 & $1585^{\circ}$ & 7. \\
\hline J. Acosta & 1590 & 1596 & 6 \\
\hline
\end{tabular}

* Tomamos en consideración 1571, año de la primera edición de la segunda parte y 1575 , cuando apareció la edición completa italiana.

entonces cuando comenzaba ese largo período vacío de ediciones italianas, que duraría hasta 1555. Cuando se reemprendió el ritmo de publicación, la obra de Oviedo se editaría inmediatamente, como hemos señalado, en el marco de las Navigationi de Ramusio (1556).

Finalmente, encontramos el caso atípico de Francisco Delicado, que publicó su obra directamente en Italia, sin mediar edición española previa. En un contexto más amplio, sin embargo, el caso no es extraordinario. Baste recordar que otras obras significativas fueron publicadas por autores españoles directamente en Italia, fundamentalmente debido a los especiales lazos políticos que unían a diversos territorios italianos con la monarquía hispánica. Así ocurrió, entre otras, con la Cosmographia de Jerónimo Girava, aparecida en Milán en 1556, o con la Historia de las cosas mas notables del gran Reyno de la China, que González de Mendoza publicó en Roma, en 1585.

\section{El centro de la difusión: Venecia}

La lectura de la tabla 3, que recoge la distribución por ciudades de las ediciones que nos ocupan, no ofrece la menor duda en señalar a Venecia 
como el centro difusor más importante de toda Italia. En efecto, siete de las diez primeras ediciones y treinta y cinco de las cuarenta y dos que en total se realizaron, salieron de las prensas venecianas.

\section{TABLA 3}

Distribución por ciudades de impresión de las ediciones italianas de obras españolas sobre historia natural y materia médica americana publicadas en el s. XVI

\begin{tabular}{lccc}
\hline Ciudad & Primeras eds. & número eds. & $\%$ \\
\hline Venecia & 7 & 35 & 83,3 \\
Roma & 3 & 4 & 9,5 \\
Florencia & - & 1 & 2,3 \\
Milán & - & 1 & 2,3 \\
Génova & - & 1 & 2,3 \\
Total & 10 & 42 & \\
\hline
\end{tabular}

Como es sabido, Venecia fue, casi desde el mismo momento de la llegada de la imprenta a territorio véneto (1469-1474) (50), uno de los centros productores de libros más importantes de Europa. En realidad, puede asegurarse que fue el primero, hasta que en la segunda mitad del siglo XVI fue sobrepasada por París (51).

En el marco estrictamente italiano, la primacía de Venecia fue absoluta durante toda la centuria: la mitad de todos los impresos italianos del siglo XVI fueron venecianos, lo que supone un número que gira en torno a las quince mil ediciones, con una media de ciento cincuenta títulos al año (52). Al iniciarse el siglo, Venecia tenía ciento cincuenta y cuatro oficinas de impresores en activo (53) y al concluirse, hacia 1596, casi quinientas personas vivían directamente de la producción editorial (54).

Si nos atenemos a la producción impresa de tema americano (o con partes importantes dedicadas al Nuevo Mundo), los datos varían un poco, aunque la tendencia es fundamentalmente la misma. Según M. Donattini (55) de un total de noventa y ocho ediciones de estas obras impresas en Italia, un sesenta por ciento (es decir, cincuenta y nueve) se publicaron en Venecia, mientras que Roma publicó quince y el resto aparecieron repartidas en varias ciudades. Ateniéndose a las primeras ediciones de las 
veintidós obras que Donattini considera, doce fueron venecianas, mientras que el resto se repartía entre Milán, Florencia y Roma.

Por lo tanto, parece indudable la preeminencia veneciana. Por razones de tipo económico, mercantil e incluso político, Venecia es lógico que aparezca como el principal centro difusor. Pero, a nuestro modo de ver, estas razones no bastan para entender la abrumadora mayoría de ediciones venecianas que los datos de la tabla 3 reflejan, que son en todo caso mayores que los que ofrecen las otras proporciones que hemos expuesto. En nuestra opinión, la configuración de Venecia como el principal centro de difusión de las obras que estudiamos debe obedecer, además de todo lo expuesto, a otro tipo de causa. Creemos que ésta debe buscarse en la actividad de diversos grupos relacionados, directa o indirectamente, con autores españoles o con el ambiente hispano. De estos grupos, el primero, en importancia y en el tiempo, fue el formado en torno a las figuras de Giovanni Battista Ramusio, Pietro Bembo y Girolamo Fracastoro, que mantuvieron una intensa relación con Gonzalo Fernández de Oviedo. En segundo lugar, la presencia de Alfonso de Ulloa entre el mundo diplomático y editorial veneciano nos parece otro elemento destacable. Por último, el especial empeño editorial de los impresores Ziletti en difundir textos sobre la materia medicinal exótica nos parece el tercer elemento en la explicación de la gran importancia de Venecia como centro difusor de textos españoles sobre Indias. Veamos con un poco más de detenimiento estos tres núcleos.

\section{Ramusio, Bembo y Fracastoro y sus relaciones con Gonzalo Fernández de Oviedo}

Es bien conocida la estrecha relación que unió a Giovanni Battista Ramusio con el cardenal Pietro Bembo y con el médico y científico veronés Girolamo Fracastoro (56). Los intereses culturales en general, literarios, pero, sobre todo, científicos que les unían les llevaron a intercambiar cartas, libros, comentarios a sus respectivas obras y dedicatorias en sus publicaciones (57). A su alrededor, se reunieron también otros hombres de la cultura veneciana y, dada la alta posición social de estos personajes, les fue posible mantener contactos con otros países europeos. Entre ellos, en un lugar preferente, la Castilla de la primera mitad del XVI, que atraía poderosamente la atención de hombres como ellos, interesados en las novedades geográficas, cosmográficas y, en general, científicas, que procedían de las recién descubiertas Indias Occidentales. 
Así pues, no es de extrañar que un hombre perteneciente a este círculo veneciano, Andrea Navagero, entre 1525 y 1528 embajador de la República en la corte castellana, fuera el primero en poner en contacto directo a sus amigos venecianos con las noticias americanas (58). En efecto, en una carta de Navagero a Ramusio, escrita en Toledo el 11 de septiembre de 1525 , éste le prometía hacerle llegar noticias abundantes sobre las Indias (59).

En el mismo Toledo, por esas fechas, Gonzalo Fernández de Oviedo escribía y mandaba imprimir a su costa el Sumario de su Natural historia de las Indias. No parece descabellado pensar que Navagero se encontrara con él, máxime si tenemos en cuenta que cuando éste regresó a Venecia, en 1528, trajo consigo un ejemplar de la edición toledana del Sumario (60). Sea como fuere, lo importante es que al regreso del embajador, Ramusio accedió directamente al texto de Oviedo y pronto se comprometió a editarlo.

Navagero murió a principios de 1529 y su hermano Bartolommeo obtuvo un privilegio de impresión para la obra de Oviedo, mediante una solicitud al Consejo de los Diez, presentada por el propio Ramusio (61). En otro documento posterior (62), la solicitud del privilegio por parte de Bartolommeo Navagero nos permite aclarar definitivamente, a nuestro modo de ver, la cuestión sobre la autoría de la traducción del Sumario. Bartolommeo expuso del modo siguiente su solicitud:

\footnotetext{
«item un libro spagnol ditto Oviedo tradotto per lui [nostro fratello] in lingua italiana che descrive tutte le cose trovate nel mondo novo cum VII disegni del detto mondo et carte da navigar de Spagnoli, et dovendole andar gran spesa et gran tempo per far il tutto corretto si supplica alla Sublimità vostra sia contenta di concedermi gratia (...) per anni venti prossimi (...)" (63).
}

Así pues, el Sumario lo había ya traducido al italiano el propio Navagero y Ramusio se debió limitar a encargarse de la edición del texto, que tendría lugar cinco años después de estos hechos. No debemos olvidar que, precisamente en 1529 y en la misma Venecia, se publicaba el opúsculo de Delicado, que reproducía el fragmento sobre el guayaco contenido en el Sumario, como hemos señalado anteriormente.

$\mathrm{Al}$ año siguiente, Ramusio entró a hacerse cargo, en calidad de sustituto de Bembo, recientemente nombrado cardenal y establecido en Roma, de la biblioteca pública que con el tiempo llegaría a ser la Biblioteca Marciana. También en el mismo año de 1530, se publicó el poema de Girolamo 
Fracastoro sobre la sífilis (64), en el que se manejaba una buena informaeión sobre los descubrimientos geográficos y el uso del guayaco, aunque Fracastoro rechazaba la tesis del origen americano de la enfermedad.

Pero, sin duda alguna, fue 1534 el año clave para situar el inicio del contacto directo del grupo veneciano con Fernández de Oviedo (65). En primer lugar, a través del texto del Sumario, publicado ese año por Zoppino. El propio Ramusio se lo hizo llegar a Bembo, a Roma (66). Fracastoro, por su parte, había escrito a Ramusio múy poco antes una carta en la que se planteaban cuestiones astronómicas (fundamentalmente sobre la posición de algunas estrellas en el hemisferio sur) y en la que el veronés sugería a Ramusio que consultaran sobre este particular a Oviedo (67). Es ésta la primera vez que encontramos citado el nombre de Oviedo en la correspondencia de estos personajes. Debe deducirse, por tanto, que el establecimiento de la relación directa con el español debió producirse entre 1530 y 1534 . A partir de esta fecha, las referencias en las fuentes son más abundantes.

En 1538, el 20 de abril, Bembo escribió directamente a Oviedo, diciéndole:

«Ho letta la vostra Istoria sopra le Indie, nella quale non solo ho scorto la meraviglia delle cose non pliù udite di quelle regioni, ma oltre a ciò ancora molta dottrina e molta prudenza vosta nelle misure del cielo e della terra e dei suoi siti» (68).

De hecho, Bembo había hecho un buen uso del Sumario al redactar, entre 1534 y 1538, el volumen sexto de sus Istorie veneziane (69). En esa misma carta a Oviedo, el cardenal se lo explicaba de este modo:

"....avendomi già alcuni anni la Patria mia dato incarico di scrivere latinamente la Istoria delle cose sue, v'ho innestato brevemente la somma di codesti vostri scoprimenti del nuovo mondo e delle sue Indie l'une e l'altre (...) Non so quanto io sia buono a far per vostra Signoria, ma come ciò sia, la prego a conoscermi per suo, ed a comandarmi» (70).

Indudablemente, Oviedo se sintió halagado por la atención que le prestaban tan ilustres personajes. En el propio texto de la Historia se refirió varias veces a Bembo, a Ramusio y a sus relaciones con ellos (71).

Pero estas relaciones fueron más allá de las cartas, las citas o los envíos de noticias. En el mismo año de 1538, cuando Bembo escribía la carta comentada, tenía lugar en Venecia, en casa de los Priuli, rica familia 
noble y comerciante, la constitución de una sociedad mercantil, ante el notario Pietro di Bartoli. Este, ayudado de la traducción de Ramusio, leía un acta redactada por Oviedo en Santo Domingo y fechada allí el 20 de diciembre de 1537. En ella se establecían las condiciones para constituir una sociedad, de la que iban a entrar a formar parte Antonio Priuli y el propio Giovanni Battista Ramusio, por un lado y, por el otro, Oviedo y otra persona a designar por él. Se constituía la sociedad con un capital inicial de cuatrocientos ducados venecianos (equivalentes a 128.200 maravedíes), que debían ser adelantados por Priuli y que se consideraban divididos en cuatro participaciones iguales, de cien ducados cada una, en manos de Oviedo, de su aún no nombrado socio, de Ramusio y del propio Priuli. La sociedad debía ocuparse de comerciar con productos venecianos, embarcados en la misma Venecia con destino Messina y Cádiz, desde donde serían enviados a Santo Domingo. Allí, Oviedo se encargaría de vender los productos y volver a cargar la nave con «liquori et zuccheri» americanos, que se exportarían a Europa. Lamentablemente, no tenemos más datos sobre el género del cargamento indiano, ni tampoco sobre la puesta en práctica de las actividades comerciales de la sociedad (72).

Hasta 1547, año en que murió Pietro Bembo, las referencias a contactos epistolares y envíos de noticias y relaciones son frecuentes. En 1539, Fracastoro escribió a Ramusio y nuevamente se refería a Oviedo:

"Io comincio a credere che molte delle cose, che noi attribuiamo al caso, et alla fortuna, no sieno cosi, ma sia il Fato, che regga le cose. Certo a caso si poteva attribuire che voi haveste ritrovato commercio con uno del Mundo Nuovo, che vi desse notitia di tante cose, che si fan di là, et non altramente ne foste istruito, che si abitaste in quel mondo" (73).

Como vemos, un hombre de la talla de Fracastoro se congratulaba de que su amigo Ramusio hubiera tenido la fortuna de conocer a Oviedo, su gran informador americano.

El mismo año en que se escribía esta carta, 1539, llegaba a Venecia como embajador español Diego Hurtado de Mendoza, hermano del entonces virrey de México. Ramusio no tardó en entrar en contacto con él y, poco después, en 1541, el embajador le hizo llegar la copia de una relación que su hermano había escrito a Carlos V sobre los orígenes de la ciudad de Tenochtitlán (74). Hacemos referençia a este hecho porque dará lugar a un nuevo intercambio epistolar con Oviedo. Esta vez fue Ramusio quien le hizo llegar hasta Santo Domingo la relación antes mencionada. Su contenido, como es natural, incitó la curiosidad de Oviedo, 
quien se puso en contacto, esta vez ya directamente, con el virrey de México. Pero no deja de ser sintomático que la primera noticia la recibiera Oviedo a través de la lejanísima Venecia, en vez de la más cercana México, de donde la fuente había partido (75).

Los envíos de Ramusio a Santo Domingo no cesaron ahí. Al año siguiente, 1540, según cuenta el propio Oviedo en la Historia General (76), el veneciano le escribió una carta en la que le anunciaba un eclipse, que sería visible desde la Española. Le enviaba, además, un ejemplar de las Tabulae de Olaus Gotho, que estaban recién publicadas en Venecia (77). Por esas mismas fechas, concretamente el 10 de mayo de 1540, el cardenal Bembo, en una carta a Ramusio, le decía:

"Quanto al libro del Signor Oviedo, qui trovo la seconda parte delle sue historie stampata nel 1534 (...). La primera parte non ci è; s'ella fosse in Vinegia state contento [di] mandarmela» (78).

Es de suponer que Rarnùusio había enviado, en 1535, sólo el Sumario y no las otras obras que se editaron conjuntamente, por eso Bembo reclama una "prima parte» que en realidad no existía, pues se trataba, como se recordará, de la versión reunida de las tres décadas primeras de Pedro Mártir de Anglería.

Un año después, en 1541, le tocó el turno de escribir a Oviedo a Girolamo Fracastoro (79). En su carta, tras elogios y muestras de respeto (80), sometía a juicio de Oviedo diversas cuestiones científicas en boga en la época. El interés de estas cuestiones confiere, sin duda, a esta carta una importancia de primera magnitud en el panorama de los debates científicos renacentistas (81).

Llegamos así al año 1543, en el que tuvo lugar el intercambio de correspondencia más interesante, a efectos de nuestro trabajo. Nos referimos a la carta que Oviedo envió al cardenal Bembo, fechada el 20 de enero de ese año, en la que se narraba la navegación por el río Marañón efectuada por Orellana. La relación fue incluida por Ramusio en el tercer volumen de sus Navigationi (1556) con el título: Di Gonzalo Fernandez d'Oviedo, Relatione della Navigatione per il grandissimo fiume Maragnon (82). De hecho, la noticia de la existencia de esta relación llegó inmediatamente a Ramusio y éste no tardó en pedirle a Bembo una copia. Así se deduce de la carta que el cardenal envió a Venecia el 27 de diciembre de ese mismo año, apenas once meses después de escribir Oviedo la suya. En ella, Bembo decía: 
«Mio Ramusio. Io farò tradur la lettera del signor Oviedo e scriverla e satisfarò il desiderio vostro" (83).

Por tanto, tampoco parece que en este caso Ramusio se tomara el trabajo de traducir a Oviedo, sino que solicitó a Bembo que alguien tradujera al italiano el texto y se lo hiciera llegar después a Venecia. Si Bembo cumplió su promesa, esa traducción debe ser la que figura en las Navigationi.

En el mismo año de 1543 se habían iniciado ya las gestiones para imprimir la recopilación ramusiana, según parece deducirse de un documento del 13 de agosto, procedente del registro del Consejo de los Diez. En él se concedía licencia a los herederos de Luc'Antonio Giunta para que pudieran imprimir una obra "nella quale si contengono molte cose di cosmographia et viagì (84). El 20 de agosto, en efecto, se concedía el privilegio por diez años para imprimir las obras contenidas en el primer volumen de las Navigationi (85), cuya salida, sin embargo, no se produjo hasta 1550, como hemos señalado.

La obtención de los privilegios para la imprenta no se detuvo aquí. El 6 de marzo de 1544, se solicitó permiso para imprimir precisamente la carta de Oviedo a Bembo (86), la cual, al parecer, ya estaba traducida al italiano, según los deseos de Ramusio. La celeridad en la obtención del privilegio puede deberse a una idea, no llevada a cabo, de imprimirla rápidamente, pero también puede indicar un deseo de evitar que un texto que levantaba cierta expectación pudiera ser publicado por otros.

La última carta que conocemos, en relación con Oviedo, es la que Bembo escribió a Ramusio el 7 de mayo de 1546 (87). En ella, el cardenal expresaba su deseo de que Oviedo se encontrara ya en España para imprimir su «nueva y hermosa obra», alusión que puede referirse a la segunda parte de la Historia general, que nunca se imprimió en vida del autor, o a la reedición de la primera parte, que tuvo lugar en Salamanca en 1547 (88), precisamente el año en que murió Bembo. Esta última carta nos indica, pues, que hasta el final el contacto entre estos personajes se mantuvo y de modo más estrecho de lo que pudiera indicar la existencia de un puñado de cartas. Debieron haber otras muchas, como se deduce de la buena información que en Venecia y en Roma se tenía sobre los movimientos de Oviedo entre Santo Domingo y la metrópoli.

Hasta aquí, pues, el mapa de la evolución de las relaciones venecianas de Oviedo, hasta donde las fuentes nos permiten reconstruirlo. Tras la muerte de Bembo no tenemos ya más referencias de contactos directos. Fracastoro murió en 1553 y Ramusio el mismo año que Oviedo, en 1557. Pero antes de la desaparición de estos dos protagonistas principales, había 
tenido lugar la edición del tercer volumen de las Navigationi, con los tres textos de Oviedo traducidos al italiano. Por primera vez, además, aparecía completa la primera parte de la Historia general. En el Discorso con el que Ramusio presentaba el volumen, dedicado precisamente a Fracastoro, no faltan alusiones a Oviedo "c'è tanto amico dell'Eccellenza Vostra» (89). Por otra parte, Ramusio vuelve a darnos otra prueba de su excelente información respecto a la obra de Oviedo, al aludir a las partes de la Historia aún no impresas:

«il (...) Sommario egli ampliò dapoi e divise en tre parti, chiamandole l'Istorie generale e naturali dell'Indie, delle quali n'è venuta in luce la prima, come si leggerà in questo volume. L'altre due (...) essendo sí coe ho inteso venuto il prefato S. Gonzalo gli anni passati dall'isola Spagnuola fino in Sibilia, per farle stampare (non so che cosa vogliano dire che sia stata cagione) con gran danno delii studiosi di questa cognitione, egli da poco da poi se n'è ritornato alla città di San Domenico nella Spagnuola, riportando seco dette due parti d'historia sopprese» (90).

Pero no sólo conocían Ramusio y Fracastoro el plan completo de la obra y los ires y venires de Oviedo (al menos hasta 1547), sino que sabían también los temas tratados en las partes aún manuscritas:

"v'erano più di 400 figure di ritratti delle cose naturali: come animali, uccelli, pesci, arbori, herbe, fiori, et frutti delle dette due parti delle Indie: il che è stato di gran perdita à gli studiosi» (91).

A continuación, se enumeraban otras cuestiones de interés tratadas en esas partes: la diferencia horaria, la latitud de México, el periplo solar anual en Nueva España, el clima, la laguna de México («in gran parte simile a quella de questa nostra gloriosa città di Venezia» (92), los problemas de la sífilis y la viruela, la mortalidad de la población indígena, los jeroglíficos que escriben los indios «come s'è veduto in quei libri che il detto S. Gonzalo mando à donare à V.E. et a me» (93), e incluso el curioso modo de contar de los incas, mediante los quippos.

Debe subrayarse claramente cómo son los temas científicos los que interesaban a los difusores de Oviedo en Italia, pese a que la Historia, como es sabido, reúne información sobre otros muchos aspectos políticos, puramente históricos, militares, etc. Esta característica debe siempre recordarse al tratar de estas obras y de su difusión europea y es una prueba indiscutible de que deben ser tenidas en consideración por los 
historiadores de la ciencia. Por otra parte, no sólo ocurrió esto con la obra de 'Oviedo, sino también con las de los otros cronistas de Indias editados en Italia.

De toda la parte inédita de la obra de Oviedo que Ramusio glosa en su Discorso, como es sabido, sólo se publicó el libro XX, pero en el año 1557, cuando ni Fracastoro, ni Ramusio, ni Bembo, ni el propio Oviedo pudieron ya verlo impreso.

Así pues, durante los años treinta, cuarenta y cincuenta, la difusión de la' obra de Fernández de Oviedo se llevó a cabo mediante las relaciones personales del autor con un activo y bien situado grupo de científicos y hombres de létras venecianos. De hecho, la difusión se detuvo cuando tanto el autor como sus amigos italianos fallecieron. De este modo, la principal fuente sobre la historia natural americana durante la primera mitad del siglo, llegó a Venecia y, en manos de personas directamente interesadas en los temas naturalísticos y científicos, recibió una acogida importante. Cuando, a mediados de siglo, las obras de los otros grandes cronistas, Cieza de León y López de Gómara principalmente, aparecieron en el panorama italiano, encontraron rápidamente un excelente campo de cultivo entre impresores, libreros y lectores venecianos. En este contexto, nos parece sintomático que la edición de las obras de estos cronistas se trasladara rápidamente desde Roma, donde tuvieron lugar las primeras ediciones, a.Venecia, desde donde se realizaron hasta seis reediciones a lo largo de la segunda mitad, como ya hemos visto.

En esos mismos años, fundamentalmente en la década de los sesentá, el panorama veneciano se enriqueció con otra edición de un cronista español, Agustín de Zárate, debida a otro personaje interesante para comprender el trasfondo de la difusión de obras españolas desde el centro editor de Venecia: Alfonso de Ulloa.

\section{Alfonso de Ulloa y su labor como traductor}

El papel de Alfonso de Ulloa como difusor de la cultura hispana en Italia ha sido puesto de relieve por diversos estudiosos (94). Su larga permanencia en Venecia (1545-1570) y su continua actividad literaria y editorial (1552-1577), lo señalan como un elemento importante a la hora de entender la propagación de determinados aspectos de la cultura literaria hispana entre el público italiano.

Sin embargo, hemos de señalar claramente que la inmensa mayoría de la producción editorial debida a Ulloa, se aleja por completo de las 
materias estrictamente científicas, dirigiéndose más bien a áreas como la literatura de creación y la historia (95). Esta característica esencial marca, pues, una diferencia sustancial con respecto al fenómeno antes descrito en torno a Fernández de Oviedo y sus relaciones venecianas, que conformaban un núcleo directamente interesdo en cuestiones científicas (96).

De todos modos, creemos que para nuestro objeto de estudio, la labor de Ulloa merece la pena ser tenida en cuenta. Su producción sobre temas geográficos se inició en 1562, con la edición de su traducción italiana de la obra del portugués Joao de Barros (97) sobre Asia y las Indias Orientales. $\mathrm{Al}$ año siguiente, salió de las prensas de Giolitto de' Ferrari, el impresor con el que colaboró más asiduamente (98), la obra de Agustín de Zárate sobre el Perú (99), que es la que más directamente interesa en este trabajo.

A través de la dedicatoria, redactada por el propio Ulloa y dirigida a Guido Brandolino, un condottiere veneciano, podemos conocer que la traducción databa de algunos años antes (100), pero que las dificultades económicas atravesadas por Ulloa le impidieron publicarla con mayor rapidez.

En cuanto a la traducción, se basa fielmente en el original castellano (Amberes, M. Nucio, 1555). Sin embargo Ulloa, como era habitual en él, apostilló en determinados pasajes el texto de Zárate, a través de pequeñas anotaciones impresas en los márgenes (101), práctica muy del uso entre los humanistas y editores de la época.

De este modo, las Historie de Zárate venían a sumarse a las otras obras españolas sobre el Perú que ya circulaban en Italia. El interés históriconatural del texto de Zárate se centra casi exclusivamente en el libro primero, especialmente en los capítulos del cuatro al ocho, ya que los otros seis libros de la crónica son fundamentalmente históricos. Desde este punto de vista, la aparición en Italia de la obra no aportó sustanciosas novedades, sino que fue un mero complemento de las obras editadas con anterioridad, especialmente, como es natural, de la más importante de ellas, la de Cieza de León, que por aquel entonces contaba ya con cuatro ediciones italianas y que aún sería reeditada en los años siguientes.

Además de a través de la obra de Cieza; la naturaleza peruana era conocida en Italia gracias a la edición ramusiana de las relaciones de Xerez y Cristóbal de Mena (1534) y a los textos que el mismo Ramusio incluyó en el tercer volumen de las Navigationi (1556) (102). Por todo ello, podemos deducir que las Historie de Zárate no conocieron más ediciones porque el interés de los lectores italianos hallaba más completa satisfacción 
en obras como la de Cieza, mucho más rica en descripciones de índole geográfica e históriconatural.

No podemos, en este apartado dedicado a Ulloa, dejar de aludir a otra de las obras de tema americano que él tradujo y que, sin duda, es la que le ha otorgado en el pasado mayor relevancia historiográfica. Nos referimos a las Historie della vita e de'fatti dell'Ammiraglio D. Cristoforo Colombo, aparecidas en Venecia, en casa de Francesco di Franceschi en 1571, pocos meses después de la muerte de Ulloa (103). La importancia de su tarea es en este caso de primer orden, puesto que no se conoce el texto castellano original, que Hernando Colón, el hijastro del Almirante al cual se atribuye la obra, nunca publicó. La edición de Ulloa es, pues, la primera y la más directa para conocer el auténtico escrito de Hernando Colón, fuera éste el autor de todo el texto o sólo de una parte (104). Por todo ello, el nombre de Ulloa debe ir inseparablemente unido al de los cronistas y narradores colombinos y al de las fuentes para conocer las circunstancias del descubrimiento europeo de las Indias Occidentales. Desde este punto de vista, aunque lejano casi siempre a los intereses científicos, Ulloa no dejó de tener un papel esencial en la difusión italiana de las novedades geográficas y naturalísticas del mundo americano.

La última obra de tema geográfico traducida por Ulloa volvió al ámbito de las Indias Orientales, tratado ya en la de Joao de Barros, traducida en 1562. En esta ocasión se trató de la Historia dell'Indie Orientali de otro portugués, Lopes de Castanheda. La traducción italiana salió a la luz algunos años después de la muerte de Ulloa; concretamente, se editó en 1577, en la casa del impresor Giordano Ziletti (105), cuyo preeminente papel en el proceso de difusión que estamos estudiando trataremos de ver a continuación.

\section{Giordano y Francesco Ziletti, editores italianos de Monardes}

En 1556, el impresor de origen bresciano Giordano Ziletti se establecía en Venecia, tras una azarosa actividad como librero de Bolonia y en Roma (106). La casa editora, all'insegna della Stella, en San Zulian, con su almacén en San Zanipolo, sestiere habitual de libreros, iban a permanecer en activo hasta 1589 (107). Durante esos treinta y cuatro años, los Ziletti - primero Giordano, hasta su muerte en 1583, luego su sobrino Francesco, activo desde 1569 hasta su muerte en 1587 y, por último, los herederos de éste- realizaron un total de doscientas veinticuatro ediciones (108). Así pues, no estamos ante grandes editores venecianos, como 
los Giunta o Giolitto, con medias anuales de más de diez ediciones, pero tampoco frente a unos modestos libreros, ya que una media de cuatro y cinco ediciones anuales sitúa a los Ziletti entre los más sólidos editores venecianos de tipo medio (109). Por otra parte, Giordano y, sobre todo, Francesco ocuparon una posición destacada dentro de l'arte delli stampatori et librari, corporación establecida en 1549, que reunía a los principales impresores y libreros de la ciudad (110). Concretamente, Francesco Ziletti llegó a ser prior del Arte en 1580 y ya había sido miembro de la junta con anterioridad y volvió a serlo en 1583 y 1586 (111). Giordano, por su parte, había destacado años atrás en la oposición corporativa contra el índice papal de 1554 y los intentos de aplicarlo en territorio de la Serenísima (112). Por último, sus relaciones de parentesco con otras casas editoras (113), típica de las corporaciones gremiales, nos completan la imagen de solidez y buena posición de la empresa en el marco de la Venecia de la segunda mitad de siglo.

Casi desde el mismo momento de la llegada de Giordano a Venecia, se iniciaron las ediciones de obras de autores hispanos relacionados con el Nuevo Mundo. Al final del período de actividad de la casa de la Estrella, habían llevado a cabo más de una docena de ediciones. Esta posición destacada de ambos Ziletti, en relación con las publicaciones de tema americano se ve realzada aún más si tenemos en cuenta que respondían, como veremos, a un plan claramente, diseñado y que, además, ambos son promotores directos de las ediciones, en la mayor parte de los casos. Por último, desde nuestro punto de vista, el protagonismo de los Ziletti cobra especial importancia al ser ellos los difusores principales de la obra del médico sevillano Nicolás Monardes, sin duda, hasta ese mómento, la aportación más importante al conocimiento de la materia médica americana (114)

Aunque ya ha ido apareciendo en los apartados anteriores, convendría ahora reunir ordenadamente la producción de los Ziletti que nos interesa directamente. La tabla 4 recoge, por orden cronológico, doce ediciones distribuidas a lo largo de treinta y dos años.

Como puede verse en la tabla, la primera edición que Giordano Ziletti llevó a cabo fue la Historia general de las Indias de López de Gómara, que ese mismo año fue publicada también por Andrea Arrivabene. A juzgar por la dedicatoria, firmada por el propio Arrivabene, la edición de Ziletti se limitó a cambiar la portada simplemente. Esta impresión queda confirmada si se cotejan algunos ejemplares de ambas ediciones. En efecto, se trata de libros idénticos en tipos de imprenta, formato, páginas, título y prolegómenos. Sólo el pie de imprenta y la marca del impresor son dife- 


\section{TABLA 4}

Ediciones de obras hispanas sobre Indias impresas por los Ziletti

\begin{tabular}{lllll}
\hline Año & Autor & Impresor & Dedicatoria & Traductor \\
\hline 1557 & Gómara (a) & Giordano & Arrivabene & no consta \\
1560 & Cieza & Giordano & - & no consta \\
1565 & Gómara (a) & Giordano & Giordano & Lo consta \\
1566 & Gómara (b) & Giordano & L. Luigini & no consta \\
1566 & Oviedo & Giordano & & \\
1575 & Monardes & Giordano & Giordano & no consta \\
& & y Francesco & Francesco & A. Ulloa \\
1577 & Castanheda & Giordano & Giordano & no consta \\
1582 & Monardes & Giordano & A. Briganti & A. Briganti \\
1582 & Monardes & Francesco & Francesco & no consta \\
1585 & Acosta & Francesco & Giordano & no consta \\
1589 & Monardes & her. Francesco & A. Briganti & A. Briganti \\
1589 & Monardes & her. Francesco & A. Brano
\end{tabular}

rentes. Este hecho nos podría hacer pensar en un acuerdo entre Arrivabene y Ziletti para sacar conjuntamente la edición, con ejemplares a nombre de uno o de otro, práctica bastante habitual en la época. Sin embargo, el privilegio y los derechos sobre la obra pertenecían, por diez años, a Ziletti, según se deduce de la concesión hecha por el Consejo de los Diez, el 20 de febrero de 1557 (115).

Tres años después, Ziletti imprimió la traducción, anónima como la anterior, de la Prima parte delle historie del Perù, de Pedro Cieza de León. De nuevo existió otra edición ese mismo año, esta vez obra de Francesco Lorenzini. En esta ocasión, sin embargo, parece claro que se trata de dos traducciones distintas, ya que esta última era firmada por Agustín de Cravaliz y un cotejo de ambos textos muestra amplias divergencias (116), además de diferir las ediciones en número de hojas y en los prolegómenos (117).

En 1565, Giordano volvió a imprimir la primera parte de la obra de Gómara, utilizando para ello la misma versión que en 1557. Al año siguiente, sacó por primera vez la traducción de Lucio Mauro de la otra obra de Gómara, la Historia de México. De este modo respondía nuevamente a la competencia, ya que en 1564, como vimos, Giovanni Bonadio había hecho imprimir de nuevo las traducciones de Cravaliz. Precisamente 
en esta edición de 1566, el propio Giordano escribía la dedicatoria de la obra y en ella exponía con bastante claridad sus intenciones y su proyecto editorial. Nos detendremos en este texto que consideramos de gran interés para conocer el programa de la casa de los Ziletti con respecto a las obras que analizamos.

La dedicatoria está firmada el 12 de octubre (fecha que no parece casual) de 1565, en Venecia, y dirigida al fraile agustino Michele Aureliano, natural, como el propio editor, de Brescia, ciudad que pese a ser geográficamente lombarda era territorio de la República veneciana en aquellos años. En el texto, Ziletti decía:

\begin{abstract}
«...havendo io meco proposto nella mia professione, di giovar al mondo, in quanto le mie deboli forze potessero, ho fatto tradurre nella nostra lingua, tra altri, alcuni libri historici, degni certamente da esser letti, i quali raccontano i maravigliosi fatti degli Spagnoli nelle Indie Occidentali, nello scoprimento, et conquista di quei paesi che per esser tanti, et cosi grandi sono stati chiamanti Mondo Nuovo...» (118).
\end{abstract}

Toda una declaración de intenciones, como se ve. Parece ser, pues, que Ziletti, que llegó a Venecia precisamente cuando Ramusio acababa de imprimir sus Navigationi, se propuso claramente seguir un programa de ediciones referidas a América, sin duda porque existía un mercado, un público lector ávido de este tipo de obras. Por eso precisamente, se trataba de un sector donde la competencia (hemos visto que entre 1557 y 1566 siempre hubo competidores para las ediciones de los Ziletti) era dura. Por este motivo, Giordano no perdió la ocasión de recordar a los lectores las obras que sobre este particular ya había impreso y las que pensaba editar en breve. Así, en la misma dedicatoria, decía:

«De'quai libri essendo state stampate da me due parti (es decir, la obra de Cieza y la primera de Gómara), ho fatto anco imprimere hora la Terza (...) et aspetti in breve la quarta parte di questa opera, scritta da chi si trovó presente, et anco le Historie del Castagneda, che contengono i fatti, de'Protoghesi nello scoprimento, et conquista de'Mari, et Terre di Oriente (...) le quali Historie ho fatto tradurre dalla lingua Portohese dal Sig. Alfonso Ulloa, gentiluomo Spagnuolo, et di perfetto giudicio in questa professione: et con lo aiuto di Dio tosto le farò delle alre historie, et cose nuove, che alle mie mani verranno» (119).

No sabemos a qué cuarta parte podía referirse Ziletti. Quizá a la segunda parte de la obra de Cieza (autor que sí estuvo presente en América 
como dice el texto), que nunca llegó a imprimirse. En cuanto a la alusión al libro de Castanheda, queda claro que aunque se refería al ámbito oriental, para Giordano entraba de lleno, como luego la obra de Cristóbal Acosta, en el mismo plan editorial. La obra no saldría impresa hasta 1577, pero gracias a esta dedicatoria podemos saber que en 1566 Ulloa ya había recibido el encargo y quizá concluido el trabajo. Como hipótesis verosímil, podemos plantear que la traducción y edición de la obra de Zárate en 1563 pudo llamar la atención de Ziletti, que decidió incorporar a Ulloa a su programa. Ello explicaría también que ésta sea una de las escasas alusiones del editor a sus traductores, normalmente silenciados y, sin embargo, aquí citado elogiosamente.

Lo cierto es que después de 1566 el proyecto pareció detenerse (120), pese a tener disponible la traducción de Ulloa, que tardó once años en salir a la luz. Precisamente, como se recordará, entre 1566 y 1575 las prensas venecianas parecía que habían perdido el interés en las obras de temas americanos. Los Ziletti, pese a sus intenciones en este sentido, también acusan esta parálisis (121). Esta momentánea paralización parece que se superó en 1575 (122), con un cambio de estrategia. Giordano, en la dedicatoria que hemos visto hablaba de "alcuni libri storici» y su producción, en efecto, se había centrado en las crónicas de Indias. El cambio de orientación en esta segunda fase le llevó a especializarse en libros sobre materia médica, más que en tratados históricos. Si exceptuamos el ya citado libro de Lopes de Castanheda, las otras obras que publicaron los Ziletti fueron tres importantísimos tratados de materia médica: el de García da Orta, el de Cristóbal Acosta y el de Nicolás Monardes. El proyecto, en sus grandes líneas, no había cambiado, pero sí había ganado en especialización. Así lo recordaba explícitamente Francesco en su aviso a los lectores de la edición del tratado de Acosta (1585):

"Volendo io seguire il buon principio dato già da M. Giordano Ziletti mio Zio nel procurar di far communi all'Italia le fatiche di quelli Autori Spagnuoli, che hanno scritto le Historie de diversi Semplici, et Animali, che nascono cosi nelle Indie Orientali, come nelle Occidentali...) (123).

Los Ziletti habían decidido abandonar las competidas reediciones de los cronistas (de hecho Cieza y Gómara aún se reeditaron en 1576, 1596 y 1599 por otros libreros venecianos) y dirigir sus apuestas hacia un terreno más especializado, pero al mismo tiempo más nuevo y con un público deseoso de recibirlo, como luego veremos. En este sentido, su apuesta puede decirse que no salió mal parada: la obra de Monardes la reeditaron 
hasta cuatro veces y sin competidores venecianos, si exceptuamos la edición sin nombre de impresor aparecida en 1576 (124), poco después de la aparición de la primera edición italiana, llevada a cabo por Giordano y Francesco, una parte cada uno, en 1575. Para las dos ediciones de 1582 se reimprimieron los textos de 1575, bajo el nombre de Giordano y 1576 - la traducción de Annibale Briganti de los textos de Orta, Clusius y Monardes- bajo el nombre de Francesco. En 1589, muertos ya los dos Ziletti, fueron los herederos de Francesco los que repitieron la doble edición, probablemente para evitar un competidor, pero también porque dos tipos de público accedían a Monardes: el más académico podía sentirse atraído por una edición en la que Clusius figuraba como glosador de varios textos, mientras que lectores interesados en aspectos más prácticos accederían al texto íntegro de Monardes, aunque sin comentario alguno.

Otro rasgo característico de esta segunda etapa en la trayectoria de los Ziletti fue, sin duda, su directo protagonismo en las ediciones. Como puede verse en la tabla 4, si exceptuamos las dos ediciones de la ver'sión de Briganti, en todas las demás fueron siempre los impresores los firmantes de las dedicatorias y silenciaron además el nombre de los traductores de los textos, hechos que indican que los costeadores de las ediciones fueron los propios Ziletti. Además, estas publicaciones incluyen diversos avisos a los lectores, escritos tanto por Giordano como por Francesco, lo que contribuye a conferirles ese papel principal.

El primer aviso al lector de Giordano Ziletti fue el de la edición de Monardes de 1575. En él, como ya dijimos, Ziletti anunciaba a sus lectores la existencia de una tercera parte de la obra y se comprometía a hacerla traducir e imprimirla tan pronto como le fuera posible. Pero, además, atacaba directamente a sus posibles competidores. En concreto, parecía dirigir sus ataques a la versión latina realizada por Clusius y publicada en Amberes el año anterior (125):

«...egli è avenuto, che alquante delle istesse cose Medicinali sono state molto alterate da alcuni, che le hanno scritte nella Lingua Latina; a me è paruto di non alterarle punto, ma farlevi vedere tali quali dal proprio Autore sono state descritte (...) et se ad altri è venuto voglia di ridurle a più brevità, poteva far di meno de aggiungervi le sue annotationi» (126).

Giordano Ziletti se mostraba orgulloso de su fidelidad al texto original y de su rapidez y buena industria al agenciarse también la segunda parte de la obra, aparecida en Sevilla en 1571 y que su sobrino Francesco publicaba al mismo tiempo que él lo hacía con la primera (127). Las 
críticas a la edición latina de 1574 eran en este sentido justificadas, pues Clusius conocía sólo la primera parte del tratado de Monardes y, como era habitual en obras de corte académico de la época, su versión latina alteraba el orden y algunos pasajes del texto original. En cuanto a la edición italiana de 1576, las críticas de Ziletti serían igualmente válidas. Annibale Briganti tradujo los dos tratados, el de Monardes y el de Orta, haciéndolos imprimir conjuntamente, aunque con portada y paginación propias. En la dedicatoria, Briganti explicaba cómo había procedido. De creerle, no se limitó a traducir del latín la edición de Clusius, sino que tradujo del castellano directamente a Monardes y del portugués a Orta, añadiendo después «unas pocas, pero ciertamente bellas» anotaciones del naturalista flamenco, traducidas, éstas sí, del latín (128). De hecho, las anotaciones figuran solamente en la parte del texto de Orta, lo que parece indicar que la versión italiana se realizó tal y como su traductor declaraba en la dedicatoria. Paradójicamente, a pesar del ataque de Giordano, la edición de Briganti terminó siendo editada en la casa de la Estrella, en 1582 y 1589 (129). Como hemos dicho anteriormente, para explicar esta constante duplicidad de ediciones italianas de Monardes deben tenerse en cuenta, además de las razones puramente mercantiles de los impresores, el hecho de que van dirigidas a públicos distintos, claramente diferenciados en esa época.

En este sentido, conviene señalar una característica esencial de estas últimas ediciones salidas de las prensas de los Ziletti. Al tratar de definir los rasgos del cambio de orientación seguido por éstos, a partir de 1575, hemos hecho alusión a la acogida que estas obras especializadas en la materia médica de las Indias pudieron tener entre un público determinado. No es este el lugar para abordar en profundidad la cuestión de los lectores, tema difícil que requiere un análisis detenido y con un método y unas fuentes de estudio más complejas. Sin embargo, sí podemos aproximarnos al entorno más inmediato que rodeaba estas publicaciones, basándonos nuevamente, en los propios libros y los indicios en ellos contenidos. De modo fundamental, las dedicatorias nos ayudan a comprender quiénes fueron los primeros destinatarios de las obras. Pese a la retórica, muchas veces hueca y falseadora, o mediatizada por intenciones más económicas que de otra índole, en estas ediciones que comentamos estos textos contienen algunos datos muy significativos.

Las ediciones de Monardes en la traducción de Briganti $(1576,1582 \mathrm{~b}$ y 1589b) llevan la dedicatoria que éste dirigió al marqués del Valle, Ferrante de Alarcón, que no reviste mayor interés, en el sentido que nos interesa aquí. Pero la última de estas ediciones incluía otro texto que sí 
merece ser comentado. Al final del tratado de Monardes, los herederos de Francesco Ziletti decidieron imprimir un aviso a los lectores muy especial. Lo firmaba Borgarutio Borgarucci y estaba dedicado a informar a los lectores de que los productos que describía y estudiaba Monardes (nada decía, por cierto, de los de la obra de Orta) podían adquirirse «appresso l'honoratissimo Spetiale et Simplicista singolarissimo M. Francesco Calceolari, spetiale alla Campana d'oro, in Verona" (130). La aparición de estos dos personajes en conexión con el nombre y la obra de Monardes nos parece muy significativa, a la hora de entender el contexto científico en el que las ediciones italianas del médico sevillano tuvieron lugar.

Borgarutio Borgarucci, originario de Urbino, pero instalado con su familia en Venecia desde 1565, era hermano de dos conocidos médicos, Giulio y Prospero (131). Sus actividades en Venecia estuvieron siempre relacionadas con el mundo editorial. Colaboró en la edición, traducción o revisión de una veintena de obras, entre las cuales figuraban diversos tratados médicos y científicos (132).

En cuanto a Francesco Calzolari, speziale de Verona, su importancia para la historia natural italiana es de sobra conocida (133). La botica de la Campana de Oro ya había sido frecuentada, en tiempos del padre de Francesco, por Girolamo Fracastoro, entre otros (134). Pero sería en los años siguientes, concretamente a partir de los años cincuenta con las dos expediciones al monte Baldo (1551 y 1554), cuando Calzolari y su establecimiento se convirtieron en el centro y punto de encuentro de los principales naturalistas italianos, especialmente el grupo de médicos y botánicos paduanos (Anguillara, Alpago, Maranta...), el boloñés Ulisse Aldrovandi y el médico imperial Pietro Andrea Mattioli (135). Completando esta red de relaciones científicas, tanto Calzolari como Aldrovandi y, por supuesto Mattioli, tuvieron en el librero veneciano Vincenzo Valgrisio, yerno precisamente de Francesco Ziletti, un centro distribuidor de correspondencia, envío de plantas, libros, etc. (136). Así pues, en la botica de este veronés y en su famosa y conocida colección y museo naturalístico, se ofrecían al público aquellos productos medicamentosos americanos que Monardes describía en su obra "senza andare alla volta dell'Indie, et con assai miglior conditione, che leggendo sù i libri», como decía Borgarucci en su propaganda (137).

Las dedicatorias de los Ziletti en las otras obras que editaron, nos ayudan a completar el cuadro que tratamos de describir. Las ediciones de Monardes por separado $(1575,1582 a, 1589 a)$ están dedicadas a Andrea Contarini y al médico veneciano Leandro Zarotto. Por su parte, la edición del tratado de Cristóbal Acosta (1585), se la dedicó Francesco Ziletti a 
Melchior Guilandino, prefecto del Orto botanico de la Universidad de Padua, amigo de Gabrielle Falloppio y personaje importante en el cultivo de la historia natural en Italia, asimismo relacionado con Calzolari y Aldrovandi (138). Afortunadamente, se conserva el inventario de la biblioteca de Guilandino, cedida en su testamento a la Biblioteca de San Marcos, de Venecia (139). Esta fuente nos ayuda a acercarnos a un personaje que podría ser el prototipo de lector especializado de las obras españolas sobre la materia americana. En efecto, en el inventario podemos ver que Guilandino poseía las obras de Monardes, la de Cristóbal de Acosta a él dedicada por Ziletti, el tratado de Fragoso (se supone que en castellano, pues no se tradujo al italiano hasta el siglo siguiente), la Historia natural y moral de las Indias de José Acosta, las Historie de Hernando Colón en la edición de Ulloa y el tercer volumen de las Navigationi ramusianas, conteniendo las obras de Fernández de Oviedo.

Así pues, el destinatario de la dedicatoria de Ziletti no es ya un prohombre de la política o un noble interesado en humanidades, sino un científico de talla, pieza importante del grupo más destacado de botánicos italianos y con inmejorable conocimiento de la producción impresa sobre historia natural y materia médica de las Indias.

\section{Conclusión}

Esta primera aproximación al problema de la difusión de las obras científicas españolas en la Italia del siglo XVI nos ha permitido, en primer lugar, conocer detalladamente las ediciones, su ritmo de aparición y la geografía aproximada de su publicación en italiano. En segundo lugar, a través del estudio de las propias ediciones hemos tratado de ofrecer, con la ayuda de otras fuentes secundarias, una visión de los grupos promotores de la difusión de las obras, tratando de comprender el contexto en el que éstas se produjeron y los intereses científicos que las rodearon.

Si tenemos en cuenta la rapidez con que las obras se tradujeron y editaron, la concentración de las mismas en círculos concretos, fundamentalmente del ámbito veneciano y los nombres que aparecieron promoviendo o acogiendo esta producción impresa, podemos obtener una imagen bastante interesante de la repercusión que los contenidos científicos de estos textos tuvieron entre el medio académico y científico italiano.

Desde nuestro punto de vista, se puede afirmar que la presencia de esta producción científica española fue importante, se mantuvo constante a lo largo de la centuria y experimentó, al mismo tiempo que lo hacía la 
propia producción hispana en su lugar de origen, una progresiva especialización, pasando desde las primeras noticias sobre el Nuevo Mundo, a las historias descriptivas de la naturaleza de las Indias, para llegar, a partir de mediados de los años setenta, al comienzo de la asimilación de la nueva materia médica, proceso que preparará importantes novedades en el terreno de los saberes médicos, que cristalizarán en la centuria siguiente.

Somos conscientes de que este trabajo representa tan sólo un primer acercamiento a estas cuestiones. Esperamos, en el marco de un programa de investigación más amplio y de carácțer colectivo(140), poder seguir profundizando en ellas. Es necesario conocer mejor el público lector de estas obras y, sobre todo, la repercusión que su difusión entre los hombres de ciencia italianos tuvieron los contenidos radicalmente nuevos que ellas ofrecían. Pero estas líneas de desarrollo requieren un tipo de estudio diverso del que aquí hemos realizado. Se impone un análisis en profundidad de las obras, al que deberá seguir necesariamente un estudio detallado de la producción propia italiana sobre estas materias. En el futuro, intentaremos continuar nuestra investigación por las líneas aquí esbozadas.

\section{NOTAS}

(1) Basándonos en nuestro repertorio de impresos científicos (LóPEZ PIÑEIRo et al. (19811986), podemos ver que de la decena de obras que estudiamos, ocho fueron publicadas en Italia por primera vez fuera de España. En cuanto a la rapidez de publicación, más adelante nos ocuparemos de ella. Por otra parte, de las setenta y seis ediciones extranjeras que estas obras conocieron en el siglo XVI, cuarenta y dos (algo más del 55\%) fueron italianas.

(2) Este trabajo ofrece algunos de los resultados de una investigación más amplia llevada a cabo, con la ayuda de una beca post-doctoral del C.S.I.C., en diversas bibliotecas y archivos italianos desde enero de 1988 a marzo de 1989. Esperamos poder ir ofreciendo otros resultados de la misma en el futuro.

(3) Delicado (1529)

(4) Una atenta lectura de la breve obra de Delicado parece indicar la existencia de una primera impresión anterior a 1529, aunque siempre posterior a 1525, año en el que la propia portada del folleto indica que se escribió la obra. En la h. 6v, Delicado afirma lo siguiente: «No puse en esta segunda estampa la composición del lectuario: no por avaricia mas por la excellencia de la cosa en la tercera estampa lo dire..... Pese a ello, no hay pruebas de la existencia de una primera edición, ni tampoco de esa eventual "tercera estampa» que proyectaba el autor.

(5) La obrita, sin embargo, tiene también partes en latín (la dedicatoria, por ejemplo) y en castellano, lengua en la que está escrita toda la parte final (h. 5r-yr), hasta las dos últimas hojas (h. 7v-8r) donde vuelve al italiano y, finalmente, al latín, al transcribir el certificado papal, de Clemente VII, sobre la enfermedad y curación, çon el tratamiento a base de guayaco, del propio autor. 
(6) Delicado (1529), h. 5

(7) Delicado (1529), h. 6.

(8) SANudo (1879-1903), vol. 52, 589-90

(9) El nombre del impresor no figura en la edición, pero la crítica bibliográfica especializada ha establecido que la obra procedía de los talleres de Niccolò Zoppino, activo en Venecia entre 1512 y 1542, según Pastorello $(1924,102)$, o entre 1505 y 1544, según Borsa $(1980,356)$.

(10) En la contraportada, el título reża así: Sumario de la naturale et general historia de l'Indie occidentali, composta da Gonzalo ferdinando de Oviedo Altrimenti di valde... il qual fu riveduto et coretto per ordine de la Maesta del Imperatore... et tradotto di lingua castigliana in Italiana.

(11) La tercera parte (como las otras dos, con paginación y portadilla propia) nos ha sido imposible conocerla directamente, al faltar en todos los ejemplares que hemos consultado. Donatrini (1980, 73-75), dice que se titula Libro ultimo del Sumario delle Indie Occidentali y que se trata de una traducción que unifica dos relaciones que atañen a la conquista de Perú, una de Francisco Xerez y otra anónima, atribuida al capitán Cristóbal de Mena.

(12) Sobre los traductores de las tres partes de la edición de 1534, se ha creado una cierta confusión entre los estudiosos. Como veremos, existen pruebas definitivas, a nuestro juicio, para afirmar que el texto de Oviedo fue traducido por Navagero, como, por otra parte, afirmaba ya PARKs (1955). Sin embargo, Donattini $(1980,75)$ cree firmemente en la autoría de Ramusio, como también lo cree Bevilacoua $(1980,371)$. Milanesi $(1985,17)$, la más reciente editora de Ramusio, por el contrario, aporta otras pruebas que apoyan la tesis de Parks y la que nosotros mantenemos aquí.

(13) Fernández de Oviedo (1535)

(14) Cieza de León (1555).

(15) LÓPEZ DE GÓMARa (1555)

(16) López de Gómara (1556). Como es sabido, esta obra de Gómara y la citada en la nota anterior fueron editadas en castellano conjuntamente. Sin embargo, se trata de dos obras diferentes, escritas con esa intención, como se deduce del hecho de que cada una lleve una dedicatoria. Por otra parte, el propio autor, en los prolegómenos de la edición castellana, así lo reconoce. Así pues, nosotros las consideramos en todo momento como dos obras diferentes, ya que además la propia historia editorial italiana de ambas obras demuestra que fueron consideradas independientes.

(17) En opinión de Romeo (1971, 54-55), la edición veneciana, que este autor considera de 1557 aunque el año de impresión es claramente 1556, es preferible a la romana de 1555 , aunque no especifica las razones de eșta preferencia. Es indudable que la edición veneciana de Arrivabene es más cuidada e incluye una Tavola delle cose piu degne et notabile compresse nella presente opera (CIEZA DE LEÓN, (1556), h. 3v-11r) lo que facilita notablemente el manejo de la obra. En cuanto a la fidelidad al texto castellano original, sin embargo, nos inclinaríamos por la traducción de Cravaliz en la edición romana de 1555.

(18) LóPEZ DE GómARA (1557). Existen ejemplares con el pie de imprenta distinto (Appresso Giordano Ziletti, all'Insegna della Stella), aunque un cotejo de los mismos demuestra que se trata de una misma edición.

(19) Esta intención del editor aparece aún más clara en los títulos de los índices: Tavola dei capitoli della seconda parte del Perù (LóPEZ DE GómARA (1557), h. 4r-9v) y la Tavola di tutte le cose notabile contenute nella seconda parte del Perù (h. 10r-18v).

(20) A nuestro juicio, como ha quedado ya apuntado en el caso de Cieza, la traducción anónima es menos fiable que la de Agustín de Cravaliz. Un ejemplo bastará para observar estas diferencias:

Asclepio-I-1991 
(traducción de Cravaliz (1556), h. 110r) "creano tune et altri arbori che punciandogli, piangono o destillano uno liquore come latte, che ritorna gomma bianca molto buona per profumare i lor Idoli, un'altro arboro manda et distilla un'humore che si mette come quaxadiglias, et è molto buono da mangiare, c'è un'altro arboro che alcuni chiamano Guarcinaa, la cui frutta par mora, et ancor che ̀̀ dura, è da mangiares.

(traducción anónima (1557), h. 118v) «nodriscono tune, et altri alberi, $i$ quali, essendo punti, lagrimano un certo licore, como latte, che ritorna in goma bianca molto buona da perfumare gli idoli. Un'altro albero nomato guarcina, il suo frutto è come mora, benche dura assai et è buono da mangiares.

Como puede verse, pese a que desde un punto de vista literario el italiano de Cravaliz no es del todo correcto, su fidelidad al texto castellano es superior. Esta podría ser una de las razones por las que la traducción de Cravaliz, inicialmente impresa en Roma, pasó a editarse también en Venecia, en competencia con la traducción anónima menos fiel al original.

(21) Cieza de León (1560a). De López de Gómara vuelven a imprimirse las dos obras, siendo consideradas como partes segunda y tercera de la obra de Cieza (López DE Gómara, (1560a) y (1560b)).

(22) Cieza de LeÓN (1560b).

(23) LóPEz de Gómara (1565) y (1566).

(24) De hecho, los mismos estudios bibliográficos especializados suministran confusas y contradictorias noticias: así, por ejemplo, TodA (1927-31, vol. 1, 402-3 y 480-482) desconoce algunas de las reediciones de Gómara y confunde algunas de las de Cieza. Tampoco Ascarell (1972) consigue aclarar satisfactoriamente las fechas de las ediciones romanas de los Dorico. Nosotros, por nuestra parte, (LóPEz Piñero et al (1981-86), vol. 2, 159-163) desconocíamos la edición de 1557 de Gómara, confundimos el año de la edición romana y no tuvimos en cuenta las ediciones de la Historia de Mexico.

(25) Zárate (1563). Sobre Alfonso de Ulloa, nos ocuparemos más adelante de su papel como difusor de obras hispanas en el ámbito italiano.

(26) Ramusio (1556), donde se contienen las obras de Oviedo (1556a), h. 44v-74r y Oviedo (1556b), h. 74v-224v.

(27) Entre ellas, dos cartas de Pedro Alvarado a Hernán Cortés, las relaciones de Cabeza de Vaca, Francisco de Ulloa y Francisco Xerez y la carta que Oviedo escribió al cardenal Pietro Bembo en 1543 narrando la navegación del río Marañón.

(28) Por extraño que parezca, dada la notoriedad de la obra, ha existido una gran confusión entre algunos autores sobre la historia editorial de las Navigationi ramusianas. El error, a nuestro juicio, parte de GRANDE $(1905,110)$ que ofrecía unas fechas para las ediciones de cada uno de los tres volúmenes que contenían varios errores. Los datos de Grande han sido repetidos acríticamente por otros estudiosos. Nosotros mismos, por lo que se refiere al tercer volumen, los repetimos (López Piñero et al, (1981-86), vol. 2, 41-42). Creemos que ahora estamos en condiciones de ofrecer los datos más concretos, que coinciden, por otra parte, con los que registran autores más especializados como CAMERINI (1962), DoNATTINI (1980) y Milanesi (1985) El primer volumen apareció en 1550 y se reeditó en $1554,1563,1588,1606$ y 1613 . El segundo no apareció hasta 1559 y se reeditó en 1574, 1583 y 1606. El tercero, por su parte, salió en 1556 y se reeditó solamente en 1565 y 1606.

(29) Ramusio (1559), h. 3r. Esta edición del segundo volumen es la primera en reconocer explícitamente la autoría de Ramusio.

(30) Luigini (1566). La parte de Oviedo está en pp. 308-310. 
(31) Oviedo (1566). El título parece indicar que la traducción al latín no la realizó Luigini.

(32) Monardes (1575). Las dos partes tienen portada y paginación propia.

(33) Publicada por primera vez en Sevilla, en 1574.

(34) Monardes (1575), h. 5v.

(35) Monardes (1570).

(36) Monardes (1571).

(37) Monardes (1576).

(38) En 1589, sin embargo, Francesco y Giordano ya habían muerto; las dos ediciones de ese año van firmadas por "gli eredi di Francesco Ziletti».

(39) Monardes (1578).

(40) Acosta (1585).

(41) $A \operatorname{costa}(1585)$, h. 24v.

(42) Acosta (1596). El privilegio de impresión para esta obra fue solicitado y concedido por diez años al traductor, el 25 de mayo de 1596, según consta en Brown (ms.), 901.

(43) Así se deduce de la advertencia de Galluci a los lectores, donde dice: "Poi che era quasi compita di stampare questa historia volgare mi venne alle mani un'altra copia Spagnola stampata in Siviglia.....

(44) Acosta (1596), h. 124v. Romeo $(1971,68)$, encuentra además algunos errores en la traducción de Gallucci.

(45) En 1605 y 1616 aparecerán en Venecia sendas reimpresiones de la traducción de Briganti. En un segundo momento, ya a partir de los años setenta, fue el capítulo sobre el tabaco el que se editó separadamente en dos ocasiones (ca.1675 y 1689).

(46) En Venecia, Bernardo Basa reeditará la.traducción de Gallucci, en 1608

(47) En la edición conjunta de los tres volúmenes de las Navigationi, llevada a cabo en Venecia, en 1606.

(48) En un futuro pensamos ampliar nuestra investigación al siglo XVII y, en concreto, a las ediciones de estos autores, que completan el cuadro general del proceso que tratamos de analizar.

(49) Las negritas señalan las primeras ediciones. En los casos de Oviedo y Gómara, al ser editadas dos obras diferentes, señalamos con (a) y (b) cada una de ellas. En los casos de Cieza y Monardes, cuyas obras se reeditaron por dos veces en un mismo año, hemos señalado este hecho con un (2). Por último, cuando la edición italiana es parcial (como ocurre con Oviedo en una ocasión y con Monardes en tres) lo hemos señalado explícitamente.

(50) Según Vianello $(1975,83)$ la llegada de la imprenta al Véneto tuvo lugar en 1469 (Giovanni da Spira) a Venecia, de allí pasó en 1741 a Treviso (a la vez que fuera del Véneto lo hacía en Ferrara, Milán, Bolonia y Génova), a Padua y Verona, en 1472 (como en Mantua y Parma), a Brescia, en 1473 (a la vez que en Cremona y Pavía) y, finalmente, a Vicenza, en 1474.

(51) Febvre-Martin (1962), 201.

(52) Pesenti (1983), 93-94.

(53) Vianello (1975), 90.

(54) GRENDLER (1983), 22

(55) Donattini (1980), 71-72. Lamentablemente, no ofrece el repertorio, ni siquiera un elenco, de las veintidós obras que considera incluibles como de tema americano.

(56) Ya desde el extenso y documentado trabajo de GRANDE (1905), se conocen prácticamente todos los detalles que las fuentes ofrecen sobre las relaciones entre este grupo de eruditos y científicos venecianos. Incluso antes, con la biografía de Ramusio, por Del Piero (1902), o las cartas de Bembo a él dirigidas, publicadas por Dall'oste-Soranzo (1875), los rasgos fundamentales de tales relaciones habían sido dados a conocer.

Asclepio-1-1991 
(57) Baste recordar que Ramusio dedicó a Girolamo Fracastoro cada uno de los tres volúmenes de sus Navigationi; más adelante, volveremos sobre la dedicatoria del tercer volumen, que consideramos de gran interés.

(58) Indirectamente, sin embargo, cabe suponer que Bembo, Fracastoro y el propio Ramusio conocieron las publicaciones que sobre el descubrimiento habian ya aparecido. en el ámbito veneciano.

(59) Milanesi (1978), 20-21. También Luccheta (1980; 485) menciona la carta, aunque da como fecha 1523; se trata indudablemente de un error, puesto que Navagero en ese año aún no había llegado a España.

(60) Así paréce opinar también López de Meneses (1958, 66-67). Sin embargo, Gerbi (1978, 193-94) no considera probable un encuentro entre ambos y argumenta como prueba el hecho de que el supuesto encuentro no aparece reflejado para nada en la obra de Oviedo.

(61) Archivio di Stato, Venezia. Capi Consiglio dei Dieci, Notatorio, reg. 10, h. 35.

(62) A.S.V., ibidem, h. 40, datado el 19 de febrero de 1529, more veneto, es decir, 1530.

(63) Ibidem.

(64) Syphilis sive de morbus Gallicus (Verona, 1530). El libro está dedicado, significativamente, a Pietro Bembo y es la primera obra impresa de Fracastoro, aunque ya circulaba manuscrita desde 1525 (GRANDE, (1905), 104). El libro III es el que está dedicado especialmente a América.

(65) La estancia de Oviedo en Italia es muy anterior a estas fechas; se produjo en plena juventud del madrileño (1497-1502) y no parece probable que conociera a sus futuros interlocutores venecianos. Cermenati (1906, 328-330) da por seguro el contacto personal de Oviedo con Bembo, nacido en 1470, y con Fracastoro, nacido en 1483 y, por tanto, seis años más joven que el español y con sólo 14 años cuando Oviedo estuvo en Italia. No nos parece probable este contacto en fecha tan temprana, no mencionado por Oviedo en sus obras, ni por los más reputados biógrafos del mismo: Amador de los Ríos (1851), Pérez de Tudela (1959) y Ballesteros (1981)

(66) Grande (1905), 179

(67) Donattini (1980), 84. El texto de la carta, publicado ya en los Carminum de Fracastoro $(1739$, vol. 1, 66), lo recoge Grande $(1905,158)$ y el pasaje donde menciona a Oviedo dice así: "Se vi paresse scriver questi dubbi al signor Oviedo, e che le scriva io, forse non saria male, et domandarli della stella ch'è nel piede destro, che è cosi notabile se ne han cognitione separata dal Crociero, o pur se è parte di quello, nè altro so dirvi di queston.

(68) La carta se halla en BЕмво (1809), vol. 7, 425.

(69) Las Istorie no fueron publicadas hasta 1809, pero sí circularon manuscritas. De hecho, la parte dedicada a las Indias Occidentales fue incluso traducida al francés e impresa en París, en 1556 (GERBI, (1978), 195).

(70) Citado por Grande (1905, 173)

(71) Así, por ejemplo, en el capítulo 7 del libro 12 y en el Proemio del libro 21 habla de Ramusio, siempre con halagos y tratamiento respetuoso. Referencias a Bembo podemos encontrar, entre otras, en el libro 29, capítulo 30, donde también aparecen Ramusio y Fracastoro. En este pasaje, Oviedo habla claramente de la que debió ser la primera carta de Ramusio, suscitada por una controversia en la Universidad de Padua sobre la viabilidad de la ruta hacia la Especiería (Indias Orientales) a través del istmo de Panamá. Bembo es elogiado en el capítulo $9 \mathrm{del}^{-}$libro 47, como "persona de grandes letras e merescimiento"; también en el capítulo 30 de libro 50, el último de la obra, vuelve a referirse a Bembo, alabando su «latinidad y lenguan.

(72) El único documento que se conoce es una copia del acta notarial de Bartoli, que se 
halla en la Biblioteca Ambrosiana, de Milán (ms. S. 99 sup., h. 182r-187v). El original, según GERBI $(1978,202)$, debió perderse en el incendio sufrido por la Cancillería Inferior en 1570. El documento fue citado por primera vez por Revelli $(1926,69-70)$ y luego por AlmaGia (1978, 237-242). La sociedad debía durar, en principio, seis años, con posibilidad de prorrogar el acuerdo, si así lo decidian las partes. A pesar de que no conocemos si la sociedad actuó en la práctica, Donatrini $(1980,95)$ señala que Ramusio triplicó sus posesiones de tierras a lo largo de su vida y presenta como atractiva hipótesis que estas adquisiciones patrimoniales fueran, en algún modo, propiciadas por los dividentos de la sociedad mercantil con Priuli y Oviedo. El mismo Donatrini $(1980,86)$ señala que los años 1537-1541 fueron un período crítico para las tradicionales rutas comerciales venecianas, dada la coyuntura bélica contra los turcos, por lo tanto, iniciativas como las de Priuli y: Ramusio pudieron tener éxito, al suponer una diversificación de la orientación comercial veneciana y atender a una demanda de productos exóticos que siempre fue de gran envergadura en la República Serenísima.

(73) Grande (1905), 157. Es evidente la alusión a Oviedo. Por otra parte, este texto parece apoyar nuestras dudas sobre un contacto directo entre Oviedo y Fracastoro, en el período de estancia en Italia de aquét, puesto que parece deducirse que el inicio de las relaciones con Oviedo correspondió a Ramusio y no a los demás.

-(74) De ella se ocupa Ramusio en el Discorso sopra viaggi per li quali sono state condotte et si potrian condurra le spetiere, que se incluye en Ramusio (1550).

(75) Oviedo se ocupó de todo este asunto y reprodujo el texto y las cartas posteriores de Antonio de Mendoza en su Historia General, concretamente en el libro 33, capítulos 50, 52 y 53.

(76) Para lo relativo al -eclipse, véase la Historia General, libro 33, capítulo 53 y, como ya dijimos, el Proemio al libro 21, donde se refiere a Ramusio como «varón notable e docto» y se enorgullece de que «șin conoscerme, me ha querido por amigo, e me ha con letras comunicado una nueva geografiai.

(77) Gerbi (1978), 195-96. Oviedo (Proemio al libro 38) dice claramente que el libro le llegó en 1540 por mediación de Ramusio y habla del interés que la descripción geográfica sobre las regiones árticas le suscitó.

(78) Recuérdese que el Sumario salió en 1534 como Libro secondo delle Indie Occidentali, siendo el primer libro la traducción de las tres primeras décadas de Pedro Mártir de.Anglería. A ella se refiere, probablemente, Bembo, porque por el mismo pasaje se deduce que el cardenal no podía conocer aún la Historia. La cita la tomamos de $C_{R O}(1982,56)$, que parece desconocer las circunstancias de la edición de 1534, así como las fuentes anteriores a 1538 sobre los contactos entre Oviedo y Bembo (CRO, (1982), 54).

(79) La carta está sin fecha, pero parece indudable que es la primera que Fracastoro escribió a Oviedo (GRANDE, (1905), 158-162). Donatrini (1980), 84 la data, como muy pronto, en 1541.

(80) "con gloria sua inmortale di si lontano e non mai più consciuto mondo sparge notizia a tutto il resto degli uomini, tenendose cosi degna Istoria, che forse nè la più bella, ne la più grata usci mai in luces. El texto es importante, a nuestro modo de ver, porque puede ser la primera referencia a la llegada de la Historia General a Venecia. Téngase en cuenta, sin embargo, que puede referirse aún al Sumario, como vimos en el caso de Bembo. Pero si la Historia se editó ya en 1535, no parece descabellado suponer que hacia 1541 era ya conocida por Ramusio y su círculo más cercano.

(81) GRANDE $(1905,158-162)$, donde se analizan pormenorizadamente las cuestiones geográficas planteadas por Fracastoro. Lamentablemente, el interés de Grande acaba en los

Asclepio-I-1991 
problemas geográficos y astronómicos, pero la carta contiene también cuestiones de interés históriconatural (FraCASTORO, (1739), vol. 1, 40)

(82) El original de la carta fue hallado por Asensio (1949) en el Archivo de la Biblioteca Vaticana.

(83) Dall'Oste-Soranzo (1875), 33. El desconocimiento de estas cartas inéditas ha llevado a algunos autores a dar por hecho probado que Ramusio fue el traductor de la carta de Oviedo.

(84) ASV, Capi Consiglio dei Dieci, Notatorio, reg. 10, h. 129. Precisamente fue Ramusio quien informó favorablemente al Consejo sobre la obra: «avuta attestatione dalli circumspetti Secretarii Ducal Zuan Baptista Ramusio et Vicenzo Rizza che (...) non vi è cosa che parli di principe alcuno se non honoratamente ne che si contra la fede nostra concedono facult:a detti heredi di posser far quella stampa.....

(85) Brown, J. (ms.), 391. En h. 563-64 se concede otro privilegio a los Giunta, esta vez por quince años, el 26 de abril de 1550.

(86) BRown, J. (ms.), 424: "in una lettura del sior Consalvo Ferrando de Oviedo scritta al reverendissimo Cardinale Bembo delle cose delle Indie non vi son cose se non modeste $e$ christiane...".

(87) CRO, S. (1982), 54.

(88) Puede que no sea casual que el impresor de esta segunda edición de la Historia general fuera Juan de Junta, de la misma dinastía de libreros que los venecianos Luc'Antonio y Tommaso, establecido en Salamanca desde hacía unos años. De todos modos, PÉrez DE Tudela $(1959,139)$ opina que la edición salmantina «no contó, a lo sumo, sino con el consentimiento de Oviedo». Su suposición se basa en "el silencio del cronista en punto a esta edición».

(89) Ramusio (1556), h. 2v. Un poco más adelante, vuelve a citarlo: «secondo egli [i.e. Oviedo] medesimo scrisse all'Eccellenza vostra questi anni" y aún nuevamente (h. $3 r$ ) "come... s'è veduto in quei libri che'l detto $\mathrm{S}$. Gonzalo mando à donare a V.E. et a me».

(90) Ramusio (1556), h. 2v.

(91) Ibidem.

(92) Ramusio (1556), h. 3r.

(93) Ibidem: Como puede verse, los envíos de Oviedo fueron mucho más numerosos de lo que puedan indicar las cartas conservadas.

(94) Fundamentalmente, los trabajos de Gallina (1955-56), Arroniz (1968) y, sobre todo, Rumeu de Armas (1973). Anteriormente, se trató la figura de Ulloa unida a la de sus obras más famosas: la edición italiana de las Historias del Almirante, de Hernando Colón; así, por ejemplo, los trabajos de HARRISE (1872), CARBIA (1930) y CioRANESCu (1960), que se ocuparon indirectamente del personaje.

(95) De las cincuenta y siete ediciones llevadas a cabo por Ulloa (ver el repertorio completo en Rumeu (197.3,3162-187) no llegan a la docena las relacionadas con temas científicos, entre las cuales los de asunto geográfico destacan especialmente.

(96) De todos:modos, existe una cierta conexión, aunque indirecta, entre estos dos círculos El personaje clave que hace de nexo es Diego Hurtado de Mendoza, embajador español en la corte veneciana y en relación con Ramusio, como hemos visto. Las relaciones con Ulloa fueron más conflictivas (Rumeu (1973), 37) pero no debe olvidarse que fue secretario de su sobrino, Juan de Mendoza, entre 1547 y 1552 . Hurtado de Mendoza es un personaje merecedor de mayor atención, en especial por sus relaciones con el mundo científico centroeuropeo e italiano. Baste recordar que en el verano de 1544, significativo si se recuerda lo que dijimos en el apartado anterior, Conrad Gesner estuvo hospedado en la casa veneciana de Mendoza (FISCHER (1966), 26-28). 
(97) Barros (1562).

(98) Entre 1552 y 1556, todas las ediciones llevadas a cabo por Ulloa, fueron impresas en casa de Giolitto. Después de 1556, el español trabajó también con otros impresores, pero mantuvo siempre una relación con quien fuera su primer protector y patrón (Rumeu (1973), 46-51); BoNGI (1890-95), 47-48, passim).

(99) ZaRATE (1563).

(100) «...havendo io tradotto gli anni passati poco avanti che comminciasi a comporre la Vita del Invitissimo Imperatore Carló Quinto, mio Signore, le presenti Historie dello scoprimento e conquista del Perù, et fattole ora stampare..." (Zarate (1563), h. 2v). Si tenemos en cuenta que la edición original castellana data de 1555 y que la publicación de la biografía de Carlos V, a la que se refiere Ulloa es de 1560, debemos situar en esos años la traducción de la obra de Zárate. Es más, la tarea debía estar lista ya en 1557, porque el 15 de julio de ese año, el Consejo de los Diez otorgó un privilegio de impresión al propio Ulloa para un «libro dell'historie et scoprimento del Perù, composto da Agustino di Zarate» (Brown (ms.), 301).

(101) Véase, en este sentido, Zarate (1563), 16. En ocasiones, la nota marginal es un simple subtítulo que anuncia el asunto tratado en el texto, pero en ésta que señalamos, como en bastantes otras, Ulloa anota el texto de modo más personal.

(102) Estas fueron las mismas que en la edición de 1534, a las que se añadió la relación d'un secretario di Francesco Pizarro fatta della provincia del Perù, detta di Nuova Castiglia, con la descrittione della gran Città del Cuscho (RAmusio (1556), h. 392-414). .

(103) No es éste el lugar para entrar en la polémica sobre la verdadera paternidad del texto castellano original, sobre la que se han planteado diversas y contradictorias hipótesis. Puede verse un resumen de la misma en Rumeu (1973), 121-125.

(104) Esta última es la tesis sostenida por Rumeu (1973, 125-131), para quien Hernando Colón es autor de los capítulos XVI al CVIII, debiendo ser atribuidos los primeros quince capítulos a un anónimo escritor, procedente del círculo de doña María de Toledo, viuda de Diego Colón.

(105) Aunque en el pie figura el nombre de Giordano Ziletti, la dedicatoria fue firmada por su sobrino Francesco. Por otra parte, fue el propio Francesco quien obtuvo el privilegio de impresión, el 26 de julio de 1577 (BROwN (ms.), 731).

(106) Según Grender $(1983,265-270)$, Giordano fue arrestado en 1548 por la Inquisición papal, en Bolonia, acusado de tener libros prohibidos. Cuando salió de la cárcel, tres semanas después, se trasladó a Roma, donde mantuvo un taller de impresor hasta 1556. Allí fue nuevamente arrestado por el Santo Oficio, acusado de vender libros prohibidos en puestos callejeros, aunque también fue puesto en libertad poco después. Durante su permanencia en Roma, había ya publicado un libro en Venecia, en 1549, pero no se estableció allí definitivamente hasta 1556.

(107) Según Ascarelli (1953, 200), los herederos de Francesco Ziletti permanecieron en activo hasta 1595; por su parte, $\operatorname{Moranti}(1977,1557)$ afirma que prolongaron el nombre de la casa hasta 1598. Sin embargo, mantenemos la fecha de 1589 como final de la labor editorial continuada de la firma Ziletti, ya que es la fecha que dan Borsa $(1980,355)$ y Partorello (1924, 101-102), que señala que las ediciones regulares desaparecieron en ese año, aunque se realizara aisladamente una única edición, en 1595.

(108) Pastorello (1924, 101-102) contabilizó 129 ediciones bajo el nombre de Giordano y 103 bajo el de Francesco y sus herederos, además de otra, en 1583, realizada conjuntamente por ambos Ziletti. Los datos que ofrece GrendLeR (1983, 22-23) son similares: 103 ediciones de Francesco y 121 de Giordano. Las ocho ediciones que añade Pastorello fueron realizadas por 
Giordano en sociedad con otros impresores. En otro lugar, GRENDLER $(1983,267)$ hace subir a 140 las ediciones de Giordano.

(109) Véase a este respecto la clasificación que ofrece GRENDLER (1983, 22-23), en la que Francesco se sitúa en el grupo de editores de la importancia de Valgrisio, mientras que Giordano (al que los cálculos de Grendler perjudican, ya que considera el año de inicio de su actividad 1549 y no 1556, cuando se estableció definitivamente en Venecia) se halla en el grupo de impresores como Andrea Arrivabene, de tipo medio. De todos modos, el propio Grendler señala que los datos deben ser considerados por debajo de las cifras reales, ya que el repertorio de Pastorello (1924), en el que se basan, presenta una tendencia a ofrecer cifras inferiores a las reales. Esta consideración debe aplicarse también a los datos ofrecidos en la nota anterior.

(110) Pesenti (1983), 97.

(111) A. S. V., Arti, B. 179/1, h. 1 y 3r, como prior; como consejero, en B. 163/1, h. 24; 13 r, donde se consigna su elección como prior; 60v y $64 \mathrm{r}$.

(112) Grendler (1983), 144.

(113) Francesco Ziletti se inició en el negocio librero comprando, en 1570, el almacén del famoso impresor Andrea Arrivabene, editor, como se recordará, de las obras de CIEZA (1556) y López de Gómara (1557): Poco antes de la compra, en 1569, Francesco se había prometido en matrimonio con una hija del impresor Niccolò Bevilacqua, pero finalmente, en 1579, se casó con la hija de Vicenzo Valgrisio, editor y librero veneciano en estrecho contacto con los ambientes científicos de la época y con personajes de la importancia de Ulisse Aldrovandi, Pietro Andrea Mattioli, Alvise Anguillara o Giaccomo A. Cortuso, entre otros.

(114) Recuérdese que la obra de Hernández permaneció en su mayor parte inédita y que sólo a partir de 1651 se publicó, parcialmente, en Italia.

(115) Brown, ms., h. 356. La fecha es de 20 de febrero de 1556, pero expresada según el more veneto (que cambiaba el cómputo del año a principios de marzo y no en enero), por lo tanto corresponde al año 1557, según nuestro cómputo. En la licencia se concede «che niun'altro che lui [i.e. Giordano Ziletti] over chi aveva causa da lui possa stampare in questa nostra città, ne in alcun luogo del Dominio nostro la prima, et seconda parte dell'historie dell'India tradutte dal spagnuol nel volgare per spatio d'anni dieci..... De ello se deduce que el privilegio alcanzaba también a la obra de Cieza de León, ya que, como se recordará, su Crónica del Perù fue considerada la prima parte, mientras que la Historia de Gómara era titulada Seconda parte delle historie generali en las diversas ediciones venecianas. Sin embargo, la obra de Cieza había sido ya editada el año anterior a esta licencia por Andrea Arrivabene y en la portada se hacía constar que este impresor tenía concedido un privilegio de impresión por veinte años.

(116) Ver, a este respecto, lo que apuntábamos en las notas 17 y 20.

(117) Parece claro, pues, que Ziletti tenía privilegio para hacer imprimir la traducción anónima, mientras que o bien Cravaliz, o bien Lorenzini, debieron obtener otro para la versión ya impresa en Roma con anterioridad. Conviene recordar que Lorenzini, en el mismo año de 1560, imprimió las traducciones de Cravaliz de las dos obras de López de Gómara.

(118) López de Gómara (1556), h. 2v-3r.

(119) LóPEz de Gómara (1556), h . 4v-5r.

(120) Ese mismo año, Giordano imprimió la edición de textos sobre la sífilis recopilados por Luigi Luigini (Aloysius Luisinus), en la que, como se recordará, se incluía la versión latina de los capítulos sobre el guayaco de la Historia General de Fernández de Oviedo.

(121) Si exceptuamos la publicación en castellano de la Cosmografia de Jerónimo Girava, realizada en 1570 . Al parecer, se trataba de una edición que no costeó Ziletti, a juzgar por la

Asclepio-I-1991 
dedicatoria de la obra, firmada por Juan de Miranda y dirigida al Comendador Juan Rodríguez de Torres.

(122) El 29 de septiembre de 1574, Giordano Ziletti presentaba el texto de Monardes y obtenía el privilegio de impresión por veinte años: BROwn, ms., h. 703-704.

(123) Acosta (1585), h. 24r.

(124) Como se recordará, la obra de Monardes aún fue reimpresa una quinta vez antes de concluir el siglo, en 1597, pero para entonces la casa de los Ziletti había ya desaparecido.

(125) Clusius (1574). Esta primera edición latina contiene solamente la primera parte de la obra de Monardes, de ahíla defensa que Ziletti realizaba de su edición italiana, que comprendía también la segunda parte.

(126) Monardes (1575), h. 6.

(127) En realidad, se trata de una misma edición de las dos partes, pero con portada y paginación propias. La asociación de Francesco al proyecto de su tío, en esta segunda fase, quedaba así establecida desde un principio, al figurar su nombre en el pie de imprenta de la portada de la segunda parte. De todos modos, la dedicatoria de ésta la seguía firmando Giordano.

(128) Monardes (1576), h. 3. El texto de Briganti dice así: «l'uno in lingua Spagnuola Castigliana scrivendo, e l'altro in lingua sua natia Portoghese (...) l'hò dalle lor lingue straniere alla nostra Italiana favella ridotti, con haverci di più tradotte alcune poche, ma certo belle annotationi di Carolo Clusios".

(129) Curiosamente, en 1582, Giordano no suprimió el Aviso a los lectores de la edición de 15.75, que contenía las críticas a la edición de Clusius.

(130) Monardes (1589b), a continuación de la p. 347, en dos hojas sin numerar.

(131) Giulio Borgarucci desarrolló la mayor parte de su actividad como médico en Londres y en los Países Bajos, dada su filiación calvinista. Su hermano Prospero, por el contrario, ejerció en territorio veneciano y publicó también varios tratados médicos. Para el tema que nos ocupa, es interesante señalar que la edición del Viaggio di Monte Baldo (Venecia, 1566) de Francesco Calzolari, está dedicada a él. También debemos señalar que Prospero colaboró en la edición de De morbo gallico (Venecia, 1566-67) de Luigini, publicada por Giordano Ziletti: FIRPO (1960- , vol. 12, 565-68).

(132) Firpo (1960- , vol. 12, 568).

(133) Tergolina (1934), Maggioni-Talmelli (1969) y Gliozzi (1960- , vol. 17, 65-67).

(134) Tergolina (1934), 293.

(135) Magginoni-Talmelli (1969), 24-26 y Tergolina (1934), 295 y ss. Para la relación entre Calzolari y Aldrovandi resulta imprescindible conocer la correspondencia mantenida entre ambos, en donde aparece reflejada toda la red de relaciones científicas mantenidas entre ambos. Cermenati (1910) publicó el epistolario, aunque sin aparato crítico ni comentarios.

(136) Palmer (1985), 101-103. El papel de intermediario de Valgrisio se refleja con especial claridad en la correspondencia entre Aldrovandi y G. A. Cortuso, publicada por DE TONI (1922).

(137) Monardes (1589b), h. 2r.

(138) Estas relaciones de Guilandino pueden rastrearse en su correspondencia con Aldrovandi, publicada por De Toni (1911). Sobre la obra científica de Guilandino, Ferrari (1959).

(139) A. S. V., Procuratoria di Sopra, Chiesa, B. 68, fasc. 4, núm. 130. El inventario está fechado el 24 de diciembre de 1589 y contiene una somera descripción de más de dos mil títulos, ordenados en una división por grandes áreas, que facilita, en cierto modo, la identificación.

(140) En este sentido, junto a otros compañeros del Instituto de Estudios Documentales e Históricos sobre la Ciencia, estamos llevando a cabo un programa de investigación sobre la 
materia médica americana y su introducción en Europa, que nos permitirá continuar aportando nuevas perspectivas en esta línea de cuestiones.

\section{REFERENCIAS BIBLIOGRAFICAS}

Acosta, C. (1585) Tratado...della historia, natura, et virtù delle droghe medicinali, et altri semplici rarissimi, che vengono portati dalle Indie Orientali in Europa... Nuovamente recato dalla spagnuola nella nostra lingua, Venetia, presso à Francesco Ziletti.

Acosta, J. (1596) Historia naturale, e morale delle Indie...nella quale si trattano le cose notabili del cielo, e degli Elementi, Metalli, Piante, et Animali di quelle: $i$ suoi riti, et ceremonie: leggi, et governi, et guerre degli Indiani. Nuovamente tradotta della lingua Spagnuola nella Italiana da Gio. Paolo Gallucci Salodiano, Venetia, presso Bernardo Bassa.

Almagia, (1937) Gli Italiani primi esploratori dell'America, Roma.

Arroniz, O. (1968) Alfonso de Ulloa, servidor de don Juan Hurtado de Mendoza, Bulletin Hispanique, 3-4 437-457.

Ascarelli, F. (1953) La tipografia cinquecentina italiana, Florencia.

Ascarelli, F. (1972) Le cinquecentine romane. Censimento delle edizioni romane del XVI secolo possedute dalle biblioteche di Roma, Milán.

Asensio, E. (1949) La carta de Gonzalo Fernández de Oviedo al cardenal Bembo sobre la navegación del Amazonas (20-1-1543), Revista de Indias, 9, 569-577.

Ballesteros Gaibrois, M. (1981) Gonzalo Fernández de Oviedo, Madrid.

Barros, J. (1562) L'Asia del.. de'fatti de'Portoghesi nello scoprimento e conquista de'mari e terre di Oriente, Venetia, Vicenzo Valgrisi.

Bемво, P. (1809) Opere, 9 vols., Milán.

Bevilacoua, E. (1980) Geografi e cosmografi, en: G. Arnaldi; M. P. Stocchi, Storia della cultura veneta. Dal primo Quattrocento al Concilio di Trento, Vicenza; vol. 2, 355-374.

Bongi, S. (1890-95) Annali di Gabriel Giolito de'Ferrari da Trino di Monferrato stampatore in Venezia, 2 vols., Roma.

Borsa, G. (1980) Clavys Typographorum Librariorumque Italiae, 1465-1600, 2 vols., Aureliae Aquensis.

Camerini, P. (1962) Annali dei Giunti. Venezia, 2 vols., Florencia.

CARbia (1930) Fernández de Oviedo, Fernando Colón, Las Casas, el señor Caddeo y yo, Nosotros, $68,59-73 ; 70,90-95$.

Cermenati, M. (1906) Ulisse Aldrovandi e l'America, Annali di botanica, 4, 313-366.

Cermenati, M. (1910) Francesco Calzolari e le sue lettere all'Aldrovandi, Roma.

Cieza de León, P. (1555) La Prima Parte de la Chronica del Grandissimo Regno del Peru. Che parla de la demarcatione de le sue provintie...li ritti e costumi de l'Indiani,... Discritta da...in Lingua Spagnuola. Et tradotta pur hora nella nostra lingua Italiana per Agustino de Cravaliz, (Al fin:) Roma, Appresso Valerio, et Luigi Dorici fratelli.

Cieza de León, P. (1556) La prima parte dell'istorie del Peru; dove si tratta l'ordine delle Provincie, delle Città nuove in quel Paese edificate, riti et costumi degli Indiani, con molte cose notabili, et degne, che vengono à notitia. Composta da... Aggiuntovi in dissegno tutt le indie con la tavole delle Cose più notabili, Venetia, appresso Andrea Arrivabene.

Cieza de León, P. (1560a) Cronica del gran regno del Peru, con la descrittione di tutte le provincie, e costumi, e riti, con le nuove città edificate, et altre strane et maravigliose notitie. Parte prima. Scritta da...in lingua Spagnuola. Tradotta nella Italiana per Agostino di Cravaliz, Venetia, per Francesco Lorenzini da Turino. 
Cieza de León, P. (1560b) La prima parte dell'historie del Perù. Dove si tratta l'ordine delle Provincie, delle Città nuove in quel Paese edificate, $i$ riti, et costumi degli consideratione. Composta da...Con la tavola delle cose piu notabili, Venetia, Appresso Giordano Ziletti.

Cieza de León, P. (1564) Historia over Cronica del gran regno del Peru...Parte Prima. Composta da...tradotta nella Italiana per Agostino di Cravaliz, Venetia, per Giovanni Bonadio.

Cieza de León, P. (1576) Cronica del gran regno del Perù, con la descrittione di tutte le Provincie, costumi, e riti. con le nuove città edificate, et altre strane et maravigliose notitie. Parte prima. Scritta da... Tradotta nella Italiana per Agostino di Cravaliz, Venetia, Appresso Camillo Franceschini.

Cieza de León, P. (1596) La Prima parte dell'historie del Perù. Dove si tratta l'ordine delle Provincia, delle Città nuove in quel Paese edificate, i riti, et costumi degli Indiani, con molte cose notabili, et degne di consideratione, Venetia, appresso Andrea Arrivabene.

Cionarescu, A. (1960) Primera biografía de Cristóbal Colón. Fernando Colón y Bartolomé de las Casas, Tenerife.

Clusius, C. (1574) De Simplicibus Medicamentis Ex Occidentali India Delatis, quorum is Medicina usus est...,Antuerpiae, Ex Officina Christophori Plantini.

CRO, S. (1982) La correspondencia epistolar entre el Cardenal Bembo y Fernández de Oviedo: implicaciones históricas, en: América y la España del siglo XVI, Madrid; vol. 1, 53-64.

Dall'Oste, L.; Soranzo, G. (1875) Lettere inedite di P. Bembo a Giovanni Battista Ramusio, Venecia.

De Toni, G. B. (1911) Intorno alle relazioni del botanico Melchiorre Guilandino con Ulisse Aldrovandi, Atti della R. Accademia di Scienze, Lettre, ed Arti degli Agiati in Rovereto, 17 149-171.

De TonI, G. B. (1922) Spigolature aldrovandiane XIX. Il botanico padovano Giacomo Antonio Cortuso nelle sue relazioni con Ulisse Aldrovandi e con altri naturalisti, en: Monografie storiche sullo Studio di Padova, Venecia; 215-249.

Del Piero, A. (1902) Della vita e degli studi di Gio. Battista Ramusio, Venecia.

Delicado, F. (1529) El modo de adoperare el legno de India occidentale: Salutifero remedio a ogni piaga e mal incurabile, Venetiis, sumptibus Francisci Delicati.

Donatrini, M. (1980) Giovanni Battista Ramusio e le sue Navigationi: Appunti per una biografia, Critica storica, $17,55-100$

Febvre, L.; Martin, H. J. (1962) La aparición del libro, México.

Fernández de Oviedo, G. (1534) Libro secondo delle Indie Occidentali, Venetia, (Niccolò Zoppino).

Fernández de Oviedo, G. (1535) Sumario de le cose de le Indie occidentale intitulado Nova Castiglia, Roma.

Fernández de Oviedo, G. (1556a) Sommario della naturale et generale Historia dell'Indie Occidentali, composta da..., en: G. B. Ramusio Terzo volume delle navigationi et viaggi..., Venetia, nella stamperia dei Giunti; h. 44v-74r.

FERNÁNDEZ DE Oviedo, G. (1556b) Della generale et naturale historie delle Indie à tempi nostri ritrovate..., en: G. B. Ramusio Terzo volume delle navigationi et viaggi..., Venetia, nella stamepria dei Giunti; h. 74v-224v.

Fernández de Oviedo, G. (1566) De guaiacomo ligno tractatus unus. De ligno sancto tractatus alter, en: L. Luigini De morbo gallico omnia quae extant apud omnes medicos cuiuscumque nationis... Tomus porior, Venetiis, apud Iordanum Zilettum; 308-310.

Fernández de Oviedo, G. (1559) Historia general y natural de las Indias, 5 vols., Madrid.

Ferrari, G. E. (1959) Le opere a stampa del Guilandino (per un paragrafo dell'editoria scientifica 
padovana del pieno Cinquecento), en: Libri e stampatori in Padova. Miscellanea di studi storici in onore di mosn. G. Belleni, tipografo editore libraio, Padua; 377-463.

FIRPO, L. (1960- ) Borgarucci, en: Dizionario biografico degli Italiani, Roma; vol. 12, 565-568.

FischeR, H. (1966) Conrad Gesner (1516-1565). Leben und Werk, Zurich.

Fracastoro, G. (1739) Hieronymi Fracastorii Carminum, 2 vols., Padua.

Gallina, A. M. (1955-56) Un'intermediario fra la cultura italiana e spagnola nel secolo XVI: Alfonso de Ulloa, Quaderni Ibero-americani, 17, 4-12; 19-20, 194-209.

GerBi, A. (19.78) La naturaleza de las Indias Nuevas, México.

Glıozzi, G. (1960- ) Calzolari, en: Dizionario biografico degli Italiani, Roma; vol. 17, 65-67.

GRANDE, S. (1905) Le relazioni geograpiche fra Pietro Bembo, Gerolamo Fracastoro, Giovanni Battista $\cdot$ Ramusio e Giacomo Gastaldi, Memorie della Società Geografica Italiana, 12, 93 197.

GRENDLER, P. F. (1977) L'inquisizione romana e l'editoria a Venezia, 1540-1605, Roma

$\mathrm{H}_{\mathrm{A} \cdot \mathrm{R} R I S E} \cdot \mathrm{H} .(1872)$ Bibliotheca americana vetustissima, Nueva York.

LÓPEZ DE GOMARA; F. (1555) Historia di Mexico, et quando si discoperse la nuova hispagna, conquistata per l'ilustriss. et valoroso Principe don Ferdinando Cortes Marchese del Valle. Scritta per...et Tradotta nel Volgare Italiano per Augustino de Cravaliz, Roma, Appresso Valerio et Luigi Dorici fratelli.

López DE GómARA, F. (1556) La Historia generale delle Indie Occidentali, con tutti li discoprimenti, et cose notabili che in esse sono successe, da che si acquistarono fino ahora. Tradotta nel volgare Italiano per Agustino de Cravaliz, Roma, per Valerio et Luigi Dorici.

LÓPEZ DE GómARA, F. (1557) La seconda parte delle historie generali dell'India, con tutte le cose notabili accadute in esse dal principio fin'à quesro giorno, et nuovamente tradotte di Spagnuolo in Italiano, Venetia, Appreso Giordano Ziletti.

López de Gómara, F. (1560a) Historia delle nuove Indie Occidentali, con tutti i discoprimenti et cose notabili, avvenute dopo l'acquiso di esse. Parte seconda...Tradotta nella Italiana da Agostino di Cravaliz, Venetia, per Francesco Lorenzini da Turino.

López de Gómara, F. (1560b) Historia di don Ferdinando Cortes, marchese della Valle, Capitano Valorosissimo, con le sue maravigliose prodezze nel tempo, che discopri, et acquistò la nuova Spagna. Parte terza...Tradotta nella Italiana da Agostino di Cravaliz, Venetia, per Francesco Lorenzini da Turino.

Lópéz de Gómara, F. (1564a) Historia delle nuove Indie Occidentali...Parte seconda..., Venetia, per Giovanni Bonadio.

López de Gómara, F. (1564b) Historia di don Ferdinando Cortes,...Parte terza..., Venetia, per Giovanni Bonadio.

LóPEZ De GómARA, F. (15 65) La seconda parte delle historia dell'India. Con tutte le cose notabili accadute in esse dal principio fin'à questo giorno, et nuovamente tradotte di Spagnuolo in Italiano, Venetia, Appresso Giordan Ziletti.

LÓPEZ DE GómARA, F. (1566) Delle historie dell'indie. Nella quale particolarmente si tratta dello scoprimento della Provincia di Iucatan detta Nuova Spagna, et delle cose degne di memoria, fatte da Spagnuoli nella conquista della grande, et maravigliosa Città di Messico, et delle altre Provincie ad essa sottoposte. Nuovamente tradotta di Lingua Spagnuola, da Lucio Mauro, Venetia, Appresso Giordano Ziletti.

López de Gómara, F. (1599) Historia dell'Indie Occidentali, overo conquista della provincia d'Iucatan, della maravigliosa città di Messico, et d'altre Provincie ad essa sottoposte. Tradotta di lingua spagnuola, da Lucio Mauro, Venetia, Barezzo Barezzi.

López de Meneses, A. (1958) Andrea Navagero, traductor de Gonzalo Fernández de Oviedo, Revista de Indias, 18, 63-72. 
López Piñero, J. M. et al (1981-86) Los impresos científicos españoles de los siglos XV y XVI, 4 vols., Valencia.

Lucchetta, G. (1980) Viaggiatori e racconti di viaggi nel Cinquecento, en: G. Arnaldi; M. P. Stocchi, Storia della cultura veneta. Dal primo Quattrocento al Concilio di Trento, Vicenza; vol. 2, 433-489.

LuiginI, L. (1566) De morbo gallico omnia quae extant apud omnes medicus cuiuscunque nationis... Tomus Prior, Venetis, Apud Jordanum Zilettum.

Maggioni, G; Talmelli, D. (1969) Prime note per un dizionario bio-bibliografico dei farmacisti veneti che si distinsero nelle scienze, lettere, arti e nella politica, Conselve (Pd).

MilaneSI, M. (1978) Introduzione, en: G. B. Ramusio. Navigazione e viaggi, Turín; vol. 1, 11-39.

Milanesi, M. (1985) Introduzione, en: G. B. Ramusio Navigazioni e viaggi, Turín; vol. 5, 11-25.

Monardes, N. (1571) Segunda Parte del libro de las cosas que se traen de nuestras Indias Occidentales, que sirven al uso de medicina... Va añadido un libro de la Nieve..., Sevilla, en casa de Alonso Escribano.

Monardes, N. (1574) Trattato della Neve e del Bere Fresco, Raccolto per M. Giovan Batista Scaranpo, del trattato del.., e ridotto in lingua Toscana, Fiorenza, Nella Stamperia di Bartolomeo Sermantelli.

Monardes, N. (1575) Delle cose che vengono portate dall'Indie Occidentali pertinenti all'uso della Medicina. Raccolte, et Trattate del...Parte Prima. Novamenta recata dalla Spagnola nella nostra lingua Italiana, Venetia, Presso di Giordano Ziletti.

Monardes, N. (1576) Due altri libri parimenti di quelle che si portano dall'Indie Occidentali... en: Due Libri dell'Historia de i Semplici, Aromati, et altre cose, che vengono portate dall'Indie Orientali, pertinenti alla Medicina... Hora tutti tradotti dalle loro lingue nella nostra Italiana da Annibale Briganti..., Venetia.

Monardes, N. (1578) Herba Tabacco, D'Indie Trattano. Da l'opere dell'... che serve per uso di medicina a ferite, piaghe vechie, ogni doglie, aposteme fredde, carboncoli, contraveneni, a li vermi, a mal di madre, ristagnar il Sangue, a fame, a sete, é ad altro. E piu la virtu del pepe longo, qual e piu Sano del pepe nero, tradutto di Spagnolo in Italiano, Genova, Apressoi Marc'Antonio Bellone.

MonARDES, N. (1582a) Delle cose, che vengono portate dall'Indie Occidentali pertinenti all'uso della Medicina. Raccolte, et tratte dal.., parte prima. Novamente recata dalla Spagnola nella nostra lingua Italiana. Dove ancho tratta de'Veneni, et della lor cura, Venetia, Appresso Giordan Ziletti.

MonaRdes, N. (1582b) Della Historia dei semplici aromati, et altre cose che vengono portate dall'Indie Occidentali, pertinenti alla medicina, en: Due libri dell'Historia dei semplici aromati, et altre cose, che vengono portate dall'Indie Orientali pertinenti all'uso della Medicina, Venetia, Appresso Francesco Zilettu,

Monardes, N. (1589a) Delle cose che vengono portate dall'Indie Occidentali, pertinenti all'uso della Medicina. Raccolte et trattate dal..., Venetia, Appresso li Heredi di Francesco Ziletti.

MonaRdes, N. (1589b) Della historia de i semplici, aromati, et altre cose che vengono portate dall'Indie Occidentali, pertinenti alla medicina, en: Dell'Historia de $i$ semplici, aromati, et altre cose, che vengono portate dall'Indie Orientali pertinenti all'uso della Medicina..., Venetia, Appresso li Heredi di Francesco Ziletti.

MONARDES, N. (1597) Due altri libri parimente di quelle cose che si portano dall'Indie Occidentali, Con un Trattato della neve et del bever fresco..., en: Dell'Historia de $i$ semplici aromati.. Con Annotationi di Carolo Clusio. Hora tutti tradotti dalle loro lingue nella nostra Italiana da M. Annibale Briganti..., Venetia, Appresso l'Heredi di Girolamo Scotto.

Moranti, L. (1977) Le cinquecentine della Biblioteca Universitaria di Urbino, Florencia.

Asclepio-1-1991 
Palmer, R. (1985) Pharmacy in the republic of Venice in the sixteenth century, en: A. Wear; K. French; J. M. Lonie The medical renaissance of the sixteenth century, Cambridge, 100-117, 303-312.

PARKs, G. B. (1955) The Contents and Sources of Ramusio's Navigationi, Nueva York.

Pastorello, E. (1924) Tipografi, editori, librai a Venezia nel secolo XVI, Florencia.

Pérez de Tudela (1959) Vida y escritos de Gonzalo Fernández de Oviedo, en: G. Fernández de Oviedo Historia general y natural de las Indias, Madrid; vol. 1, 7-15.

Pesenti, T. (1983) Stampatori e letterati nell'industria editoriale a Venezia e in Terraferma, en: G. Arnaldi; M. P. Stocchi Storia della cultura veneta. Il Seicento, Vicenza; vol. 1, 93-129.

Ramusio, G. B. (1550) Primo volume delle navigationi et viaggi..., Venetia, nella stamperia dei Giunti.

Ramusio, G. B. (1556) Terzo volume delle navigationi et viaggi..., Venetia, nella stamperia dei Giunti.

Ramusio, G. B. (1559) Secondo volume delle navigationi et viaggi..., Venetia, nella stamperia dei Giunti.

Revelli (1926) Terre d'America e archivi d'Italia, Milán.

Romeo, R. (1971) Le scoperte americane nella conscienza italiana del Cinquecento, MilánNápoles.

Rumeu de Armas, A. 91973) Alfonso de Ulloa, introductor de la cultura española en Italia, Madrid.

Sanudo, M. (1879-1903) Diarii. A cura di R. Fulin, F. Stefani, N. Barozzi, G. Berchet e M. Allegri, Venecia.

Tergolina, V. (1934) Francesco Calzolari speziale veronese, Bolletino dell'Istituto Storico Italiano dell'Arte Sanitaria, 6, 14; 293-310.

Toda I GülLE, E. (1927-31) Bibliografia Espanyola d'Italia dels origens de la Imprempta fins a l'any 1900, 5 vols., Castell de San Miguel d'Escornalbon.

Vianello, N. (1975) La prima diffusione della stampa nel Veneto, en: 1474. Le origini della stampa a Vicenza, Vicenza; 83-93.

Zarate, A. (1563) Le Historie... dello scoprimento et conquista del Peru... Nuovamente di lingua Castigliana tradotte dal S. Alfonso Ulloa, Vinegia, Appresso Gabriel Giolito de'Ferrari. 